\title{
CORIUM COOLABILITY UNDER EX-VESSEL ACCIDENT CONDITIONS FOR LWRS
}

\author{
MITCHELL T. FARMER*, DENNIS I. KILSDONK and ROBERT W. AESCHLIMANN \\ Nuclear Engineering Division, Argonne National Laboratory \\ 9700 S. Cass Avenue, Argonne, IL U.S.A. \\ "Corresponding author. E-mail : farmer@anl.gov
}

Received May 27, 2009

\begin{abstract}
In the wake of the Three Mile Island accident, vigorous research efforts were initiated to acquire a basic knowledge of the progression and consequences of accidents that involve a substantial degree of core degradation and melting. The primary emphasis of this research was placed on containment integrity, with: i) hydrogen combustion-detonation, ii) steam explosion, iii) direct containment heating (DCH), and iv) melt attack on the BWR Mark-I containment shell identified as energetic processes that could lead to early containment failure (i.e., within the first 24 hours of the accident). Should the core melt fail the reactor vessel, then non-condensable gas production from Molten Core-Concrete Interaction (MCCI) was identified as a mechanism that could fail the containment by pressurization over the long term. One signification question that arose as part of this investigation was the effectiveness of water in terminating an MCCI by flooding the interacting masses from above, thereby quenching the molten core debris and rendering it permanently coolable. Successful quenching of the core melt would prevent basemat melt through, as well as continued containment pressurization by non-condensable gas production, and so the accident progression would be successfully terminated without release of radioactivity to the environment. Based on these potential merits, ex-vessel corium coolability has been the focus of extensive research over the last 20 years as a potential accident management strategy for current plants. In addition, outcomes from this research have impacted the accident management strategies for the Gen III+ LWR plant designs that are currently being deployed around the world. This paper provides: i) an historical overview of corium coolability research, ii) summarizes the current status of research in this area, and iii) highlights trends in severe accident management strategies that have evolved based on the findings from this work.
\end{abstract}

KEYWORDS : Corium Coolability, Light Water Reactor, Severe Accident

\section{INTRODUCTION}

Following the Three Mile Island reactor accident in 1979 , the focus of LWR safety research shifted to address beyond-design-basis accidents, which have become to be known as 'severe accidents.' In particular, efforts were initiated to acquire a basic knowledge of the progression and consequences of those accidents that involve a substantial degree of core degradation and melting. [1] The primary emphasis of this research was placed on containment integrity, with: i) hydrogen combustiondetonation, ii) steam explosion, iii) direct containment heating (DCH), and iv) melt attack on the BWR Mark-I containment shell identified as energetic processes that could lead to early containment failure (i.e., within the first 24 hours of the accident). [2] Should the core melt, or 'corium' fail the reactor vessel, then non-condensable gas production from Molten Core-Concrete Interaction (MCCI) was identified as a mechanism that could fail the containment by pressurization over the long term. One signification question that arose as part of this investigation was the effectiveness of water in terminating an MCCI by flooding the interacting masses from above, thereby quenching the molten core debris and rendering it permanently coolable. Successful quenching of the core melt would prevent basemat melt through, as well as continued containment pressurization by non-condensable gas production, and so the accident progression would be successfully terminated without release of radioactivity to the environment. Based on these potential merits, exvessel corium coolability has been studied extensively over the last 20 years to support accident management planning for the current plants. Furthermore, findings from this research have impacted the accident management strategies for the Gen III + plants that have been designed and are currently being deployed around the world.

The principal objective of this paper is to review the status of R\&D in the area of debris coolability under ex- 
vessel accident conditions, and to summarize the impact that this research has had on advanced plant designs. To this end, a description of coolability phenomenology is provided first, followed by a summary of the database that underlies this interpretation. Based on these results, an assessment of the extent to which core debris may be rendered coolable by top flooding is then provided. The paper then closes with a short summary of how the findings from this research have impacted the development of accident management strategies for Gen III+ plants that are currently being deployed.

\section{COOLABILITY PHENOMENOLOGY}

Several heat transfer mechanisms have been identified through experiments that can contribute to long-term corium coolability. These mechanisms are summarized in Table 1, while a physical illustration is provided in Fig. 1. When water is introduced atop an MCCI, the question of whether or not a significant amount of the thermal energy is initially removed will depend upon whether a stable crust is able to form that inhibits heat transfer from the melt to the water layer. For a stable crust to form, two necessary conditions must be met [3]: (i) a thermal condition, viz., the melt/water interfacial temperature must fall below the corium freezing temperature, and (ii) a mechanical condition, viz., the incipient crust must be stable with respect to local mechanical loads imposed by the agitated melt. If either of these two conditions is violated, then stable crust formation is precluded. In this bulk cooling regime, efficient melt/water heat transfer occurs due to conduction and, predominately, radiation heat transfer across the agitated (i.e., area enhanced) melt/water interface, in addition to entrainment of melt droplets into the water overlayer.

As bulk cooling heat transfer continues, the melt temperature gradually declines. As the downward heat transfer rate decreases, then melt sparging arising from

Table 1. Summary of Coolability Mechanisms Observed in MACE Integral Tests

\begin{tabular}{|c|c|c|}
\hline Mechanism & Description & Experimental Evidence \\
\hline Bulk Cooling & $\begin{array}{l}\text { Melt sparging rate is initially high enough to } \\
\text { preclude stable crust formation at melt/water } \\
\text { interface. As a result, high heat transfer rates } \\
\text { occur due to conduction and, predominately, } \\
\text { radiation across the agitated (area enhanced) } \\
\text { interface. This phase is terminated when a } \\
\text { stable interfacial crust forms. }\end{array}$ & $\begin{array}{l}\text { High heat transfer rates measured during early } \\
\text { phase of the melt-water interaction. Data } \\
\text { indicates that a coherent crust cannot form; } \\
\text { rather, crust segments are broken up and mixed } \\
\text { into melt. }\end{array}$ \\
\hline Melt Eruptions & $\begin{array}{l}\text { Melt dispersal occurs by an entrainment } \\
\text { mechanism in which concrete decomposition } \\
\text { gases carry melt through defects in the crust to } \\
\text { the overlying coolant. The dispersed material } \\
\text { is quenched and forms coolable particle beds } \\
\text { and high surface area volcanic formations. }\end{array}$ & $\begin{array}{l}\text { Eruptions observed in all tests conducted with } \\
\text { limestone-common sand concrete after incipient } \\
\text { crust formation. The particle beds are } \\
\text { characterized by high porosity and large particle } \\
\text { size. }\end{array}$ \\
\hline Water Ingression & $\begin{array}{l}\text { Corium shrinkage from an initially molten to a } \\
\text { fully quenched state amounts to } \sim 18 \mathrm{vol} \% \text {. } \\
\text { This causes voids/defects to appear in the } \\
\text { frozen material. Water penetrates down through } \\
\text { the voids/defects, augmenting the otherwise } \\
\text { conduction-limited heat transfer process. }\end{array}$ & $\begin{array}{l}\text { Melt/water heat flux far exceeds that which } \\
\text { could be transferred by conduction across the } \\
\text { (up to } 10 \mathrm{~cm} \text { ) thick crusts formed during the } \\
\text { tests. Posttest measurements indicate that crusts } \\
\text { are permeable to both gas and water flows. }\end{array}$ \\
\hline Crust Breach & $\begin{array}{l}\text { Due to water ingression, thick crusts will form } \\
\text { and bond to the reactor cavity walls. These } \\
\text { crusts will not be stable in the typical } \sim 6 \mathrm{~m} \\
\text { span of most plants. Thus, they will periodically } \\
\text { fail, leading to renewed cooling by the above } \\
\text { three mechanisms. }\end{array}$ & $\begin{array}{l}\text { Partial crust failure and relocation events } \\
\text { observed in MACE integral effects tests. Various } \\
\text { structural - mechanical analyses have shown } \\
\text { that crusts will not be stable at reactor scale. }\end{array}$ \\
\hline
\end{tabular}




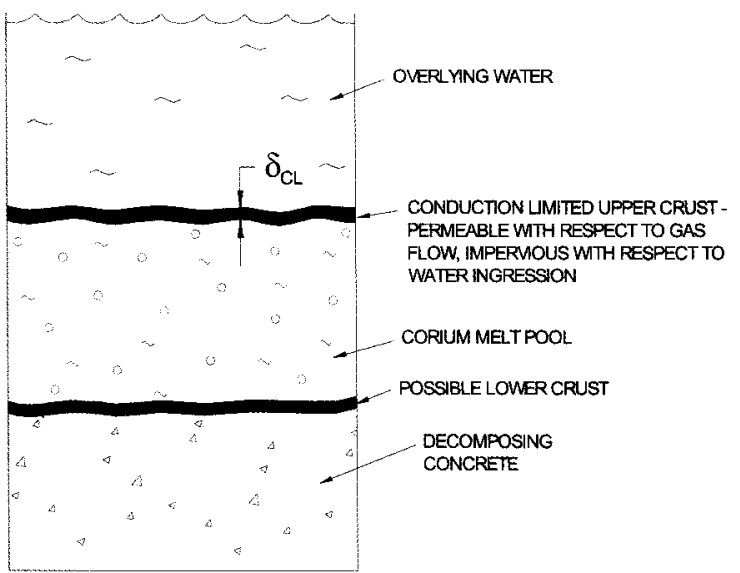

(a)

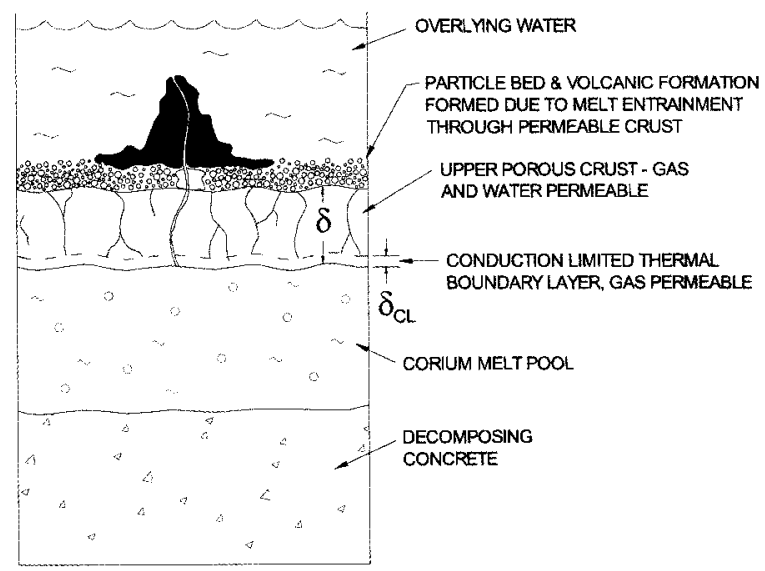

(b)

Fig. 1. (a) Traditional View of CCI with Conduction-limited Upper Crust at Melt Water Interface; (b) CCI with Water Ingression and Melt Eruption Cooling Mechanisms

concrete decomposition also decreases. Thus, a point will eventually be reached at which the thermal and mechanical thresholds for interfacial crust formation are both satisfied, and an insulating crust forms between the coherent melt zone and water layer. The physical configuration at this point consists of an ongoing MCCI at reduced temperature with a crust atop the melt (Fig. 1(a)). The crust will be characterized by some degree of porosity, or cracks, owing to the necessity of venting concrete decomposition gases.

After incipient crust formation, completion of the quench process can only be achieved if one of two conditions is met. The first condition is that the melt depth lies below the minimum depth at which decay heat can be removed via conduction heat transfer alone $(\sim 10 \mathrm{~cm})$. This case is trivial, and is not addressed in any further detail. The second condition is that water is able to penetrate into the debris by some mechanism to provide sufficient augmentation to the otherwise conduction-limited heat transfer process to remove the decay heat. Three potential mechanisms have been identified through experiments which provide pathways for water to penetrate the debris. The first mechanism is water ingression through interconnected porosity or cracks (Fig. 1(b)). This process relies on crack propagation through the material and, as such, is highly dependent upon the mechanical properties, since thermal stress is a key factor. The second mechanism is particle bed formation through "volcanic" eruptions. In this case, concrete decomposition gases entrain melt droplets into the overlying coolant as they pass through the crust. The entrained droplets then solidify in the overlying coolant and accumulate as a porous particle bed atop the crust. The third mechanism is mechanical breach of a suspended crust. In particular, the thick crusts that form from water ingression could bond to the reactor cavity walls, eventually causing the melt to separate from the crust as the MCCI continues downwards. However, this configuration is not expected be mechanically stable due to the pour mechanical strength of the crust in comparison to the applied loads (i.e., the crust weight itself, plus the weights of the overlying water pool and the accumulating dispersed material). Eventually the suspended crust will fail, leading to rapid ingression of water beneath the crust. This sudden introduction of water will provide a pathway for renewed debris cooling by the bulk cooling, water ingression, and melt eruption cooling mechanisms.

The extent to which these various mechanisms can be effective in thermally stabilizing the molten core debris is principally a function of melt depth and the timing of water addition into the cavity. Further considerations in this regard are provided after reviewing the phenomenological database.

\section{PHENOMENOLOGY DATABASE}

The objective of this section is to review and assess principal findings from experiment programs devoted to investigating coolability under the conditions of top flooding. The database includes experiments conducted with both low and high temperature simulants, and with prototypic reactor materials. Low temperature simulant experiments were conducted by Theofanous et al. [4] to identify phenomena associated with melt coolability, while high temperature simulant experiments have been conducted at Sandia National Laboratories by Blose et al. $[5,6]$ to investigate coolability with concurrent concrete 
erosion. In terms of reactor material testing, the COTELS, $[7,8]$ MACE, $[9,10]$ and $\mathrm{OECD} / \mathrm{MCCI}$ programs $[11-16]$ have been completed or are underway to investigate the mechanisms of coolability under prototypic MCCI conditions. The results obtained from both the simulant and reactor material test programs are summarized below. In terms of presentation, the discussion of the MACE test results is somewhat expanded since data from this test series has been sparsely reported in the literature.

\subsection{Simulant Material Database}

To identify phenomena associated with melt coolability, Theofanous, Liu, and Yuen [4] conducted tests using glycerin and liquid nitrogen to simulate the melt and overlying coolant, respectively. Gas sparging from MCCI was simulated by purging air through a porous plate located at the bottom of the apparatus. Fission product decay heat was simulated by the sensible heat deposited in the glycerin due to cooling of the purged gas from the inlet temperature to the melt pool temperature. Experiments were conducted in two different geometries; namely, cylindrical and square test sections. In the cylindrical tests, the diameters of the two test sections were 15 and $45 \mathrm{~cm}$. For the rectilinear test sections, three different scales were investigated: $70 \mathrm{~cm} \times 70 \mathrm{~cm}, 100 \mathrm{~cm} \times 100 \mathrm{~cm}$, and $120 \mathrm{~cm} \times 120 \mathrm{~cm}$. Key parameters varied in the test matrix included the initial melt depth, the mode of gas sparging (i.e., continuous vs. pulsed), and the magnitude of the sparging rate.

The key results of the experiments of Theofanous et. al [4] can be summarized as follows. For the small scale tests conducted in the circular geometry, quench was not achieved due to the formation of wall-anchored crusts which inhibited the melt-coolant interaction. However, for the larger tests, quench was generally achieved. In particular, the data indicates that the time to quench increases with initial melt depth and decreases with increasing sparging rate. The principal mechanism leading to coolability in these experiments was volcanic eruptions. These eruptions led to enhanced debris surface area available for contact with the overlying coolant. This same phenomena was first identified through reactor material experiments under MCCI conditions. $[9,10]$

Three melt coolability experiments were also conducted at Sandia National Laboratories with sustained heating and concurrent concrete erosion. These experiments include the SWISS tests, [5] conducted with stainless steel melts interacting with limestone/common sand (LCS) concrete, and the WETCOR test [6] conducted with an oxide simulant that also interacted with LCS concrete.

The SWISS apparatus consisted of an interaction crucible, melt generator, and a water delivery system. The system also contained instrumentation to measure aerosol and noncondensable gas release both before and after water was added to the test section. The $\mathrm{MgO}$ interaction crucible was cylindrical with an ID of $21.6 \mathrm{~cm}$. The concrete basemat was located at the bottom of the crucible. The melt was produced by induction heating of a $46 \mathrm{~kg} 304$ stainless steel charge mass in a melt generator located over the crucible. After the melt was formed, it was dropped into the crucible to initiate the test. Fission product decay heat was simulated with induction heating of the metal charge. Water was added over the melt at a preselected time, and the depth over the melt was maintained at $\sim 30 \mathrm{~cm}$. The heat flux to the overlying water was measured by the mass flowrate of the coolant and the differential temperature rise across the water inlet and outlet plenums.

For the SWISS-1 test, water was added very late in the sequence due to test occurrences. Thus, this was basically a dry MCCI experiment with minimal coolability data obtained. For SWISS-2, a total of $44.2 \mathrm{~kg}$ of melt was delivered to the test section. The initial temperature was between 1530 and $1686{ }^{\circ} \mathrm{C}$ at the time of delivery, based on data from thermocouples in the charge. Net input power was maintained at 60 to $70 \mathrm{~kW}$ throughout the balance of the test. The corresponding power density was $1500-1700 \mathrm{~W} / \mathrm{kg}$ of fuel, which is $\sim 5$ times the anticipated power level of $\sim 300 \mathrm{~W} / \mathrm{kg}$ for a typical PWR at 2 hours into the accident sequence. Water was added to the test section at 1.6 minutes past melt delivery. The peak melt/water heat flux was measured as $1.4 \mathrm{MW} / \mathrm{m}^{2}$. After steady state conditions were established, the basemat erosion rate was $\sim 27 \mathrm{~cm} /$ hour, while the melt-water heat flux was $\sim 0.8 \mathrm{MW} / \mathrm{m}^{2}$. Comparison of the SWISS- 1 and SWISS-2 ablation results indicates that, for these experiments, water addition had little influence on the basemat erosion rate. However, posttest examinations indicated that a bridge crust ranging from 5.1 to $6.4 \mathrm{~cm}$ thick had formed. This crust spanned the width of the test section and was anchored to the test section sidewalls. As a result, an intervening gap developed between the melt and crust as the MCCI progressed downward. This nonprototypic gap may have adversely affected the quench progression in this experiment, as indicated by the data of Theofanous et. al. [4] As an important aside, the aerosol data indicated an effective decontamination factor (DF) of $\sim 10$ for the $30 \mathrm{~cm}$ deep water pool maintained over the debris during the test.

The WETCOR test [6] utilized an apparatus similar to that used for the SWISS tests. The MgO interaction crucible was slightly larger, with an ID of $33.0 \mathrm{~cm}$. The basemat was also made from LCS concrete. In contrast to the SWISS tests, the melt was generated by in-situ heating of a $34.1 \mathrm{~kg}$ oxide charge (76.8/16.9/4.0/0.9/0.5 $\mathrm{wt} \% \mathrm{Al}_{2} \mathrm{O}_{3} / \mathrm{CaO} / \mathrm{SiO}_{2} / \mathrm{Fe}_{2} \mathrm{O}_{3} / \mathrm{MgO}$ ). The sidewall heating elements consisted of tungsten susceptor rings which were inductively heated. This approach was intended to eliminate crust anchoring to the test section sidewalls after water addition, as occurred during the SWISS tests, by maintaining the sidewalls above the freezing 
temperature of the melt. After the melt was generated and concrete ablation established, the cavity was flooded, thus initiating the experiment. Fission product decay heat after water addition was simulated by maintaining input power to the sidewall heating elements.

Key results for the WETCOR test are summarized as follows. The sidewall heating technique resulted in a non-uniform ablation front at the time of water addition; i.e., the ablation depth had reached $\sim 4.3 \mathrm{~cm}$ at the center of the test section, $0 \mathrm{~cm}$ at the mid radius, and $\sim 2.6 \mathrm{~cm}$ along the outer periphery near the tungsten susceptor coils. The cavity was flooded at 529 minutes into the test. The net input power to the melt after water addition was estimated as $28 \mathrm{~kW}$; the corresponding specific power density was $\sim 0.61 \mathrm{~W} / \mathrm{cm}^{3}$. Addition of water resulted in an initial, intense bulk cooling phase which lasted 1-2 minutes. The thermocouple data suggests that the melt temperature was reduced by $\sim 100{ }^{\circ} \mathrm{C}$ during this time. Dispersion of melt droplets into the overlying coolant was visible during bulk cooling. After the initial intense heat transfer period, a stable crust formed thereby reducing the heat transfer to the overlying coolant. The melt/water heat flux was estimated as $0.52 \pm 0.13 \mathrm{MW} / \mathrm{m}^{2}$. After crust formation, the thermocouple data indicated that the temperature stabilized in a range of $1480-1580{ }^{\circ} \mathrm{C}$. The sidewall of the test section failed 26 minutes after water was added, leading to a pressurized melt runout from the test section. Posttest disassembly revealed the presence of a 3 to $5 \mathrm{~cm}$ wide gap between the top crust and the underlying solidified debris. As for the SWISS tests, this finding indicates that the crust had anchored to the test section sidewall after water was added, which may have influenced the cooling behavior. The WETCOR aerosol data indicated an effective DF in the range of 3 to 15 for the $\sim 30 \mathrm{~cm}$ deep water pool maintained over the debris during the test.

\subsection{Reactor Material Database}

\subsubsection{COTELS Experiments}

A total of 10 reactor material experiments to investigate Fuel Coolant Interaction (FCI) and debris coolability were carried out within the framework of a joint study between NUPEC and the National Nuclear Center (NNC) in Kazakhstan. [7,8] Each experiment was conducted in two phases; i.e., test series "B" investigated $\mathrm{FCl}$ aspects of the initial water injection onto molten corium, while the follow-on series " $\mathrm{C}$ " tests investigated the long-term aspects of MCCI with continual water injection.

Key elements of the COTELS tests are summarized in Table 2. In these tests, a total of $\sim 60 \mathrm{~kg}$ of material containing $\mathrm{UO}_{2}, \mathrm{ZrO}_{2}, \mathrm{Zr}$, and stainless steel was heated in an induction furnace to nominally $2930^{\circ} \mathrm{C}$. The corium was then poured into a concrete crucible through a nozzle to simulate the reactor pressure vessel failure stage of a severe accident. The 2-D cylindrical concrete crucibles were all fabricated from basaltic concrete, which is similar to siliceous. Two different size crucibles were used (i.e. 26 and $36 \mathrm{~cm}$ ID). After the material was poured, decay heat was simulated with a second induction heating coil located around the crucible. Water was added after a preselected time by either a spray or a jet type nozzle. The heat flux to the overlying water was measured by a steam condensation system. A gas sampling system was also provided to measure offgas composition as a function of time. The temperature and pressure of the vessel plenum gas space were also monitored.

Two different corium compositions were considered in the test matrix. The first composition (Type A) consisted of $78 / 17 / 5 \mathrm{wt} \% \mathrm{UO}_{2} / \mathrm{ZrO}_{2} /$ stainless steel. This composition was only used for one experiment in the series (Test B/C-2). The second composition (Type B) was used in the remaining nine tests; it consisted of $55 / 5 / 25 / 15$ wt $\% \mathrm{UO}_{2} / \mathrm{ZrO}_{2} / \mathrm{Zr} /$ stainless steel. The Type A composition was selected due to its similarity to the TMI-2 core melt composition. The Type B composition mocked up a $22 \%$ oxidized BWR core melt containing 15 wt $\%$ stainless steel. For this particular mixture, the fuel and cladding form a pseudo-binary oxide phase with a solidus/liquidus temperature range of approximately $1900{ }^{\circ} \mathrm{C}$ to $2200^{\circ} \mathrm{C}$, respectively. [17] Thus, for the nine tests conducted with this composition, the initial temperature of $\sim 2930^{\circ} \mathrm{C}$ during the fall stage corresponded to a superheat of $\sim 730^{\circ} \mathrm{C}$ with respect to the oxide phase liquidus.

As shown in Table 2, the test matrix consisted of parametric variations on the corium composition, crucible diameter, power input level, water injection method, and the timing of water inlet. The $75 \mathrm{~kW}$ heating level used for the majority of the tests corresponds to a power density of $\sim 11 \mathrm{~W} / \mathrm{cm}^{3}$, or about 11 times prototypic decay heat level. [7] The increased power level was selected such that the basemat erosion rate in the experiment matched that expected at plant scale based on 2-D transient heat conduction analysis in the concrete. [7]

In terms of results, no steam explosions occurred during the nine experiments in which water was added atop the melt. The steady-state melt/water heat flux was reported to range from 0.2 to $0.7 \mathrm{MW} / \mathrm{m}^{2}$. In all cases, both the concrete sidewalls and base of the crucible were eroded. In addition, an interstitial pebble bed formed at the interface of the core material and the concrete; the bed was composed of concrete decomposition products [7] (presumably the aggregate). The depth of this pebble bed was found to increase with increasing ablation depth. The depth of the discolored concrete region surrounding the decomposed pebble bed was also found to increase with ablation depth. Posttest examinations revealed the important finding that crust anchoring with subsequent melt/crust separation did not occur for any of these tests, 
Table 2. Test Conditions and Results for COTELS Experiment Series

\begin{tabular}{|c|c|c|c|c|c|c|c|c|c|c|}
\hline \multirow{3}{*}{ Parameter } & \multicolumn{10}{|c|}{ Test Number } \\
\hline & B/C-5a & $\mathrm{B} / \mathrm{C}-\mathbf{5}$ & $\mathrm{B} / \mathrm{C}-4$ & $\mathrm{~B} / \mathrm{C}-2$ & $\mathrm{~B} / \mathrm{C}-3$ & B/C-10 & B/C-6 & $\mathrm{B} / \mathrm{C}-7$ & B/C-8 & B/C-9 \\
\hline & \multicolumn{10}{|c|}{ Test Conditions } \\
\hline Corium type $^{\mathrm{a}}$ & B & $\mathrm{B}$ & $\mathrm{B}$ & A & B & $\mathrm{B}$ & $\mathrm{B}$ & $\mathrm{B}$ & $\mathrm{B}$ & $\mathrm{B}$ \\
\hline Concrete trap diameter, $\mathrm{cm}$ & 26 & 26 & 36 & 36 & 36 & 36 & 36 & 36 & 36 & 36 \\
\hline Power input to debris, $\mathrm{kW}$ & $\sim 0$ & 75 & 75 & 75 & 75 & 75 & $\sim 0$ & 75 & 75 & 75 \\
\hline \multicolumn{11}{|l|}{ Water Inlet Conditions: } \\
\hline Injection method & - & Jet & Jet & Jet & Jet & Jet & Jet & Jet & Jet & Spray \\
\hline Flowrate, liters/min & 0 & 2.0 & 2.0 & 2.0 & 2.0 & 2.0 & 2.0 & 2.0 & 2.0 & 2.0 \\
\hline Inlet temperature & - & room & room & room & room & room & room & room & room & room \\
\hline Injection time delay, min & - & 8 & 8 & 8 & 15 & 15 & 8 & 8 & 8 & 8 \\
\hline & \multicolumn{10}{|c|}{ Test Results } \\
\hline Posttest debris classification & \multicolumn{3}{|c|}{$\begin{array}{c}\text { Case (1): } 20-40 \% \text { particle } \\
\text { bed formation }\end{array}$} & \multicolumn{3}{|c|}{$\begin{array}{c}\text { Case (2): } 70-80 \% \text { particle } \\
\text { bed formation }\end{array}$} & \multicolumn{4}{|c|}{ Case (3): no particle bed formation } \\
\hline \multicolumn{11}{|l|}{ Solidified debris conditions: } \\
\hline Total mass ${ }^{\mathrm{b}}, \mathrm{kg}$ & 47 & 56 & 56 & 45 & 46 & 58 & 53 & 52 & 42 & 51 \\
\hline Particle debris bed, $\mathrm{kg} / \mathrm{wt} \%$ & $9 / 19$ & $22 / 38$ & $19 / 34$ & $35 / 78$ & $33 / 72$ & $48 / 83$ & none & none & none & none \\
\hline Stone-like debris ${ }^{\mathrm{c}}, \mathrm{kg}$ & 0 & 0 & 6 & 0 & 0 & 18 & - & - & - & - \\
\hline Sand-like debris ${ }^{\mathrm{d}}, \mathrm{kg}$ & 9 & 21.5 & 13 & 35 & 33 & 30 & - & - & - & - \\
\hline Median dia. sand-like debris, $\mathrm{mm}$ & 0.6 & 0.8 & 2.2 & 1.5 & 1.0 & 0.4 & - & - & - & - \\
\hline lower ingot mass, $\mathrm{kg}$ & 38 & 34.5 & 37 & 10 & 13 & 10 & 53 & 52 & 42 & 51 \\
\hline \multicolumn{11}{|l|}{ Eroded concrete conditions: } \\
\hline Max. axial/radial erosion, $\mathrm{mm}$ & $13 / 28$ & $10 / 25$ & $25 / 22$ & $15 / 15$ & $15 / 20$ & $48 / 40$ & $8 / 15$ & $10 / 18$ & $8 / 15$ & $\sim 0 / 10$ \\
\hline Max. thickness pebble bed, mm & 12 & 15 & 21 & 18 & 15 & 15 & 10 & 12 & 12 & 5 \\
\hline
\end{tabular}

${ }^{\mathrm{a}}$ Type A: 78/17/5 wt\% $\mathrm{UO}_{2} / \mathrm{ZrO}_{2} /$ Stainless Steel; Type B: 55/5/25/15 wt \% $\mathrm{UO}_{2} / \mathrm{ZrO}_{2} / \mathrm{Zr} / \mathrm{Stainless} \mathrm{Steel;}$

'Total mass of accumulated debris after the test;

'Particles larger than $16 \mathrm{~mm}$ diameter;

${ }^{\mathrm{d} P a r t i c l e s}$ smaller than $16 \mathrm{~mm}$ diameter.

which may have been attributable to sidewall decomposition.

As shown in Table 2, the tests were classified [7] in terms of the debris mass which was rendered in the form of a particle bed above the remaining corium layer. In particular, Case (1) corresponds to formation of a particle bed containing $20-40 \mathrm{wt} \%$ of the total debris mass, Case (2) corresponds to $70-80 \mathrm{wt} \%$ of the debris, while Case (3) corresponds to no particle bed formation. For experiments in which particle bed formation occurred (Cases 1-2), the depth of the bed was found to increase with increasing basemat erosion depth, and with increasing melt specific power density. Particle bed depths ranged from 7 to $12 \mathrm{~cm}$. In the Case (3) tests, no particle bed formation occurred; these experiments were characterized by relatively low power density. The mechanism by which these particle beds formed (e.g., entrainment by concrete decomposition gases) was not identified as part of this work.

The coherent solidified corium layer remaining over the basemat was always found to contain cracks and crevices which axially spanned the depth of the layer. The test results indicate that water was able to penetrate into these cracks and crevices during the test, in addition to penetrating into the intervening gap formed at the sidewall corium-concrete interface. In fact, the cooling mechanisms of water ingression through interstitial porosity and particle bed formation were of sufficient magnitude to effectively quench the core material and terminate the MCCI, as evidenced by thermocouple measurements in the basemat. However, the relative contributions of water ingression at the sidewall versus that in the central region to the overall debris cooling rate 
was not quantified. Thus, it is not clear how to extrapolate these favorable results to plant conditions, since the relative contribution of water ingression at the sidewall would be greatly reduced at that scale.

This was an important experiment series in that the results showed that the melt could be quenched under certain conditions. However, in the interpretation of the results, the following conditions should be noted which may (or may not) have influenced the test outcomes: i) specific power density was $\sim 10$ times higher than that expected at plant scale, and ii) the initial superheat of the melts was nominally $700{ }^{\circ} \mathrm{C}$ with respect to the oxide liquidus at the initial temperature of $2930^{\circ} \mathrm{C}$.

\subsubsection{MACE Experiments}

As part of an international consortium, a series of coolability experiments were conducted at Argonne National Laboratory. The principal program objective was to explore the possible benefits of massive addition of water to an MCCI already in progress insofar as: i) quenching and stabilizing the heat generating core melt, and ii) arresting or even terminating basemat ablation. Four operationally successful integral experiments were conducted in this program; test specifications are provided in Table 3. Early tests M0 and M1b were conducted with $70 \%$ oxidized PWR melt compositions, while the later tests M3b and M4 were conducted with fully oxidized core melts. Three tests in the matrix were conducted with LCS concrete, while the fourth test was conducted with siliceous concrete. A principal parameter in the matrix was test section lateral span, which was varied from $30 \mathrm{~cm}$ $\times 30 \mathrm{~cm}$ up to $120 \mathrm{~cm} \times 120 \mathrm{~cm}$. Core melt masses in these various scale tests ranged from 130 to $1950 \mathrm{~kg}$.

The experiment system (Fig. 2) consisted of a test apparatus, a power supply for Direct Electrical Heating (DEH) of the corium, a water supply system, a steam collection and condensation system, and a ventilation system to filter and exhaust the off-gases. The apparatus for containment of the core material consisted of a test section which was $\sim 3 \mathrm{~m}$ tall with a square internal crosssection. The concrete basemat was located at the bottom of the test section (Fig. 3). The basemat was instrumented with multi-junction thermocouple assemblies to track ablation front location and melt temperatures. In three of the four tests, the sidewalls of the apparatus were constructed from inert $\mathrm{MgO}$, and so the tests were essentially 1-D. However, the M0 test was conducted with concrete walls also, and therefore provided data on 2-D erosion characteristics.

The corium powder charge was placed directly on top the basemat. In tests $\mathrm{M} 0$ and $\mathrm{M} 1 \mathrm{~b}$, the charge was a mixture of crushed $\mathrm{UO}_{2}$ pellets and $\mathrm{ZrO}_{2}$ powders, plus a small amount (typically $8 \mathrm{wt} \%$ ) of calcined concrete powders $\left(\mathrm{CaO}\right.$ and $\left.\mathrm{SiO}_{2}\right)$. The concrete was incorporated to account for concrete erosion which is expected to occur during the corium spreading phase following breach of the reactor pressure vessel. [18] The melt pool was produced by initially forming a local melt zone near the top of the bed with tungsten starter coils that were electrically heated. Thereafter, the melt became the conductor, and the rest of the powders were gradually melted using DEH over several hours. For tests M3b and M4, the DEH technique for melt production was replaced by specially designed exothermic mixtures that, upon ignition, produced the

Table 3. MACE Test Specifications

\begin{tabular}{|c|c|c|c|c|}
\hline \multirow{2}{*}{ Parameter } & \multicolumn{4}{|c|}{ Test } \\
\hline & Mo & M1b & M3b & M4 \\
\hline Corium type & $70 \%$ oxidized PWR & $70 \%$ oxidized PWR & $100 \%$ Oxidized BWR & $100 \%$ Oxidized BWR \\
\hline Concrete type & LCS & LCS & LCS & Siliceous \\
\hline Test section int. dimensions & $30 \mathrm{~cm} \times 30 \mathrm{~cm}$ & $50 \mathrm{~cm} \times 50 \mathrm{~cm}$ & $120 \mathrm{~cm} \times 120 \mathrm{~cm}$ & $50 \mathrm{~cm} \times 50 \mathrm{~cm}$ \\
\hline Test section sidewall material & Concrete & $\mathrm{MgO}$ & $\mathrm{MgO}$ & $\mathrm{MgO}$ \\
\hline Initial melt mass (depth) & $130 \mathrm{~kg}(15 \mathrm{~cm})$ & $480 \mathrm{~kg}(25 \mathrm{~cm})$ & $1950 \mathrm{~kg}(20 \mathrm{~cm})$ & $480 \mathrm{~kg}(30 \mathrm{~cm})$ \\
\hline Initial Melt Temperature & $1730^{\circ} \mathrm{C}$ (estimate) & $1800^{\circ} \mathrm{C}$ & $1830^{\circ} \mathrm{C}$ & $1930^{\circ} \mathrm{C}$ \\
\hline Melt formation technique & $\mathrm{DEH}$ & $\mathrm{DEH}$ & Chemical reaction & Chemical reaction \\
\hline Specific power (actual) & $700-1400 \mathrm{~W} / \mathrm{kg}$ & $350 \mathrm{~W} / \mathrm{kg}$ & $300 \mathrm{~W} / \mathrm{kg}$ & $300 \mathrm{~W} / \mathrm{kg}$ \\
\hline Ablation depth at flooding & 1.3 & 5.0 & 1.3 & 3.8 \\
\hline Water collapsed pool depth & $50 \mathrm{~cm}$ & $50 \mathrm{~cm}$ & $50 \mathrm{~cm}$ & $50 \mathrm{~cm}$ \\
\hline Inlet water flowrate/temp. & $10 \operatorname{lps} / 20^{\circ} \mathrm{C}$ & $21 \mathrm{ps} / 20^{\circ} \mathrm{C}$ & $2 \mathrm{lps} / 20^{\circ} \mathrm{C}$ & $2 \mathrm{lps} / 20^{\circ} \mathrm{C}$ \\
\hline DEH power operating mode & Constant voltage & Constant voltage & Constant voltage & Constant voltage \\
\hline
\end{tabular}




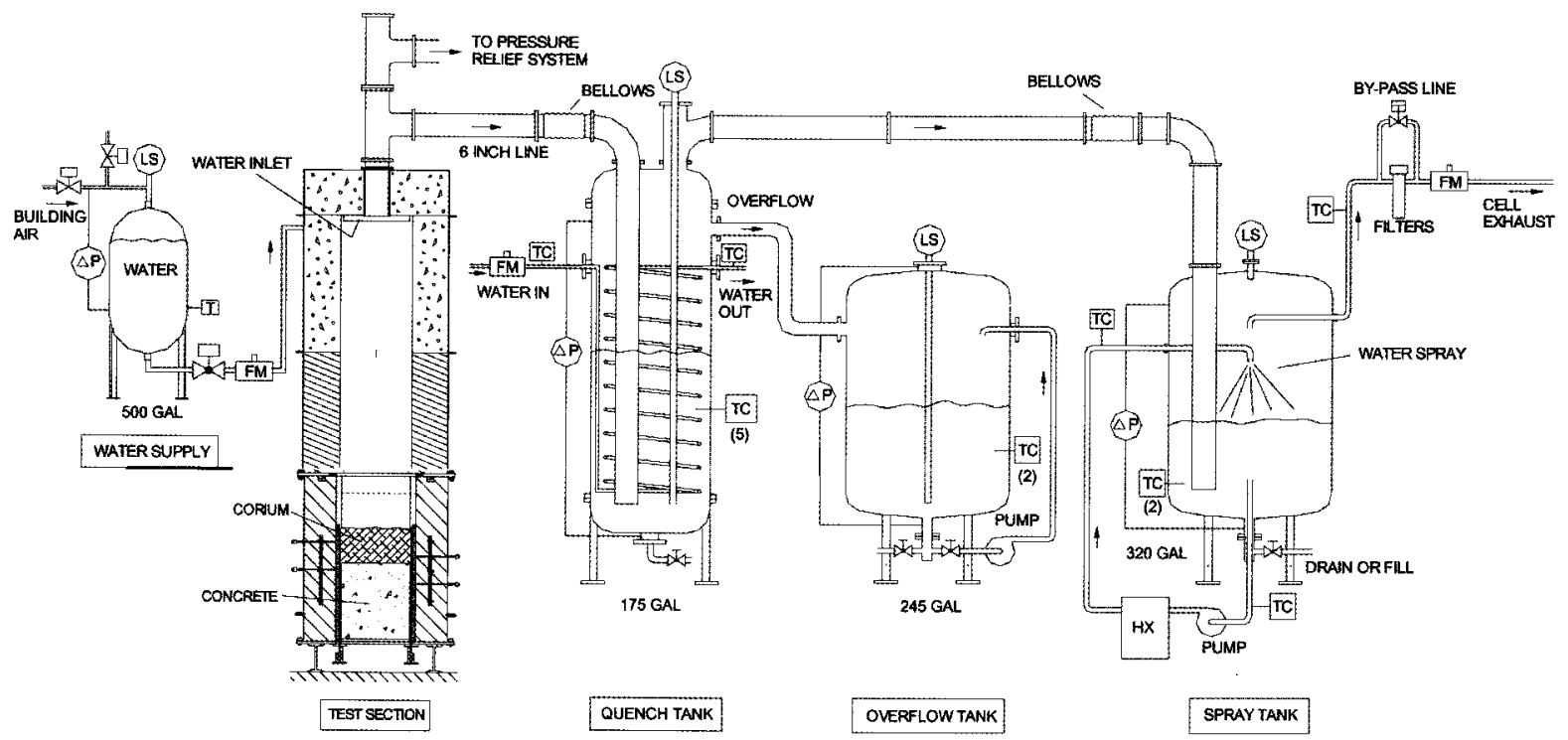

Fig. 2. MACE and OECD/MCCI Large Scale Test Apparatus

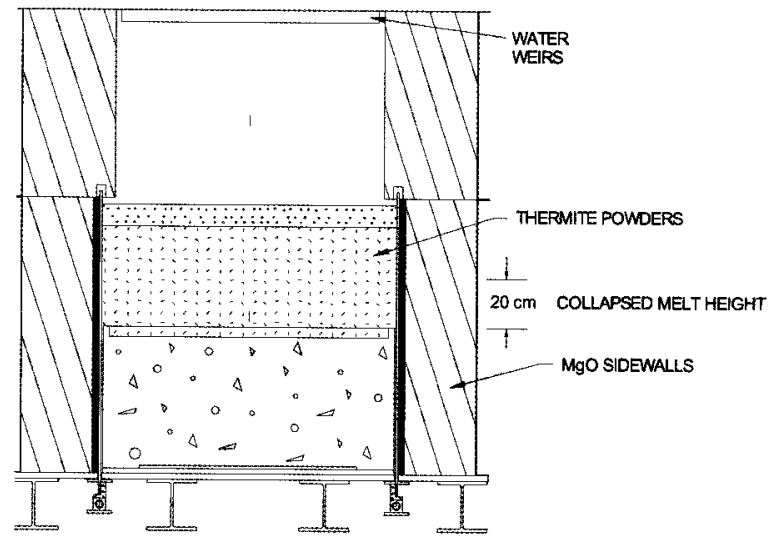

(a)

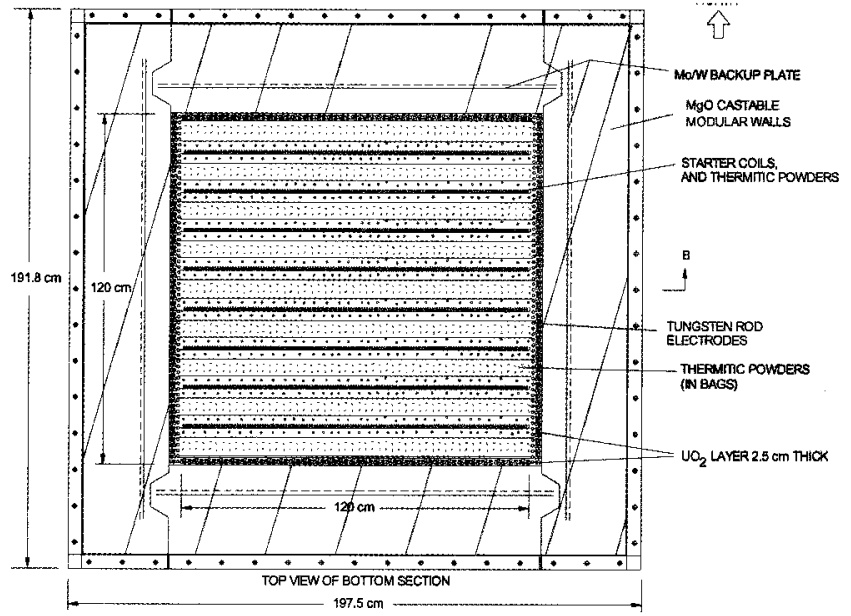

(b)

Fig. 3. (a) Side and (b) Top Views of the MACE Lower Test Section (M3b Test Section Shown)

target core melt composition over a timescale of $\sim 30$ seconds. This revised approach was developed to meet the program objective of bringing core melt in sudden contact with pristine concrete, as is expected to be the case during a plant accident.

Once the melt was produced and a specified depth of concrete erosion was achieved, the cavity was flooded. In all tests, water was delivered at a sufficient rate to ensure that the quench process would not be water-starved (i.e., sufficient to sustain a quench rate of at least $10 \mathrm{MW} / \mathrm{m}^{2}$ ).
During this phase of the test, power supply operation was switched from constant power to a constant voltage mode. This was due to the fact that core material that is quenched is not effectively heated using DEH. However, operation in a constant voltage mode maintained the specific power density in the remaining melt zone at the target level. Thus, if significant debris quenching occurred, the input power would decrease while operating in this manner.

Steam and non-condensable gases from the interaction 
were vented through a series of quench tanks and finally an offgas system. This part of the facility was instrumented to quantify the corium quenching rate (based on the steam condensation rate), as well as the gas composition and flow rate from core-concrete interaction. A summary of the principal results from the four MACE tests are provided below.

The objectives of the Scoping Test were to: i) provide an early indication of the mode and extent of corium quenching, and ii) provide information to aid both model development and future experiment design activities. The test scale (i.e. inner crucible dimension) was chosen to be slightly larger than that used in the SWISS tests [5] to reduce the chances of crust anchoring. The Scoping test was also conducted with concrete sidewalls, based on the rationale that any crust material which formed would be less likely to anchor to an ablating sidewall.

Water addition in M0 began when the basemat ablation depth reached $1.3 \mathrm{~cm}$ (i.e., at 4.0 minutes). The

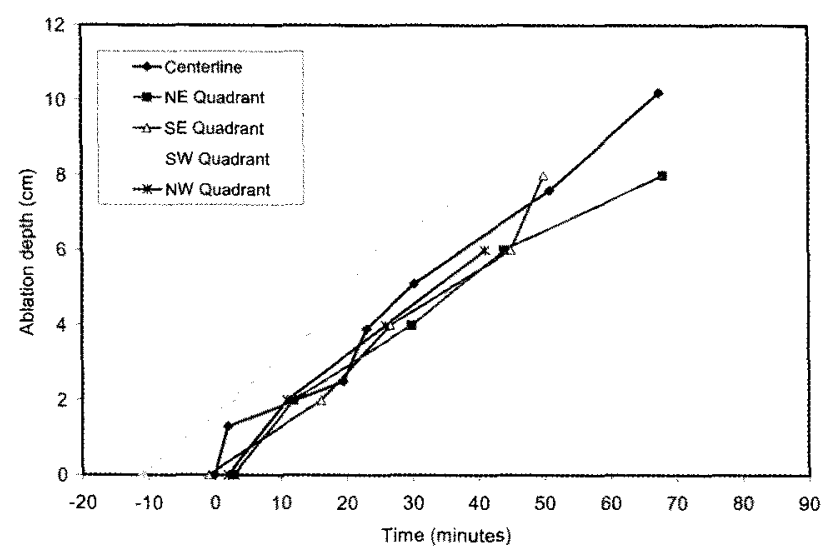

Fig. 4. M0 Axial Basemat Ablation Data

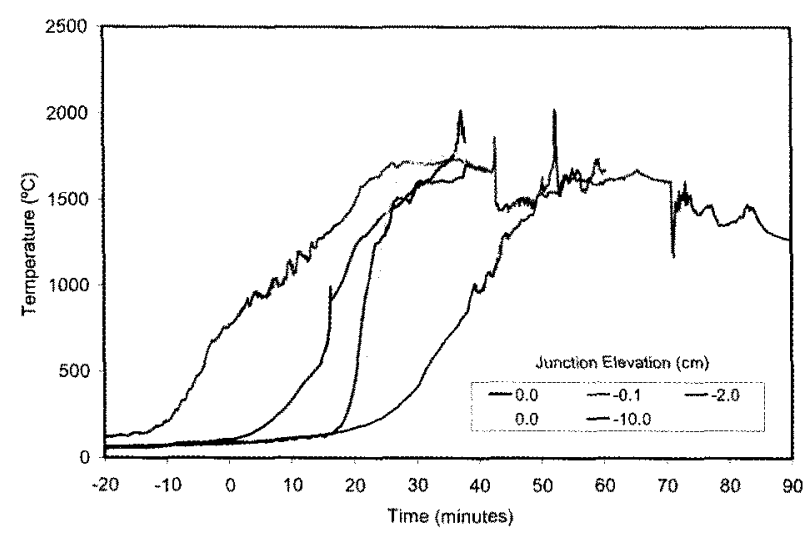

Fig. 5. M0 Melt Temperature Data ablation front location vs. time is shown in Fig. 4. At this point, the melt surface camera indicated that the pool was agitated and that there was no evidence of a crust on the pool surface. The experimenters did not observe the intense interaction phase that typically accompanies the $\mathrm{Zr}$ oxidation stage of a dry core-concrete interaction, [19] and so the input power was left at the heatup level of $100 \mathrm{~kW}$ rather than reducing it to the target level of $26 \mathrm{~kW}$. As a result, the input power ranged from 2 to 4 times the target level of $\sim 300 \mathrm{~W} / \mathrm{kg}$ fuel. A direct measurement of the melt temperature at onset of ablation was not obtained (Fig. 5). However, during posttest examinations, remnants of unmelted $\mathrm{Zr}$ rod initially present in concrete inserts over the basemat were recovered, which indicates that the melt temperature was probably below the $\mathrm{Zr}$ melting temperature of $1857^{\circ} \mathrm{C}$. Incomplete melting of the $\mathrm{Zr}$ rod would explain the absence of an intense initial interaction at the onset of ablation.

The net melt/water heat flux for MO is shown in Fig. 6, along with the DEH input power normalized with the initial test section planar area $\left(0.09 \mathrm{~m}^{2}\right)$ for comparison. The data indicates that during the first three minutes of the interaction, a large cooling transient occurred with the upwards heat flux peaking at nearly $4 \mathrm{MW} / \mathrm{m}^{2}$. The energy extraction during this phase amounted to $\sim 44 \mathrm{MJ}$, which theoretically (based on an assumed corium heat of fusion of $300 \mathrm{~kJ} / \mathrm{kg}$ ) could have rendered the initial $130 \mathrm{~kg}$ corium charge as a solid mass, albeit at high temperature. Due to the absence of functioning melt temperature thermocouples at this time, the extent of this initial interaction could not be independently verified. However, the data does indicate that a significant cooling transient occurred. In the next three minutes, the heat flux fell rapidly and a quiescent period was observed. This occurrence is attributed to the formation of a stable interfacial crust (i.e., the large initial heat removal caused the melt temperature and sparging rate to decline to the point where a crust could form in the presence of the

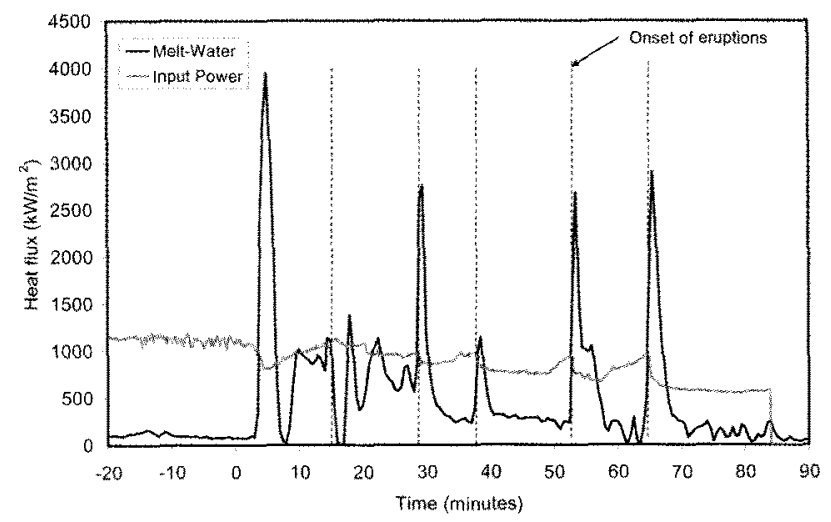

Fig. 6. M0 Melt/water Heat Flux Data 
sparging gas). Although perturbations occurred, the heat flux over the next 30 minutes averaged $\sim 700 \mathrm{~kW} / \mathrm{m}^{2}$, which amounts to $\sim 70 \%$ of the DEH input heat flux of $1 \mathrm{MW} / \mathrm{m}^{2}$. After $\sim 30$ minutes, the average heat transfer diminished steadily to a level of $\sim 150 \mathrm{~kW} / \mathrm{m}^{2}$ at the end of the test.

Posttest examinations indicated that the crust was anchored by the tungsten electrodes. The crust remained at the elevation where it initially formed. As the MCCI progressed downward, an intervening gap formed between the melt and crust, which most likely terminated efficient heat transfer processes between the debris and water. For this particular test, crust-melt separation probably occurred at $\sim 30$ minutes into the test sequence, as evidenced by the rapid decline in the heat transfer rate at this time. Despite this, ejections of molten corium through the bridge crust were observed (Fig. 6). These ejections were driven by concrete decomposition gases, which caused pool swelling and entrained melt through the crust into overlying water in the form of dispersed droplets. These droplets quenched as they settled through the water pool and collected on the crust upper surface to form a particle bed (Fig. 7). By the end of the test, the bed depth had reached $\sim 10 \mathrm{~cm}$. The top half was loosely packed while the bottom half was sintered agglomerate. The mass of the bed was $\sim 23 \mathrm{~kg}$, which amounts to $\sim 20 \%$ of the initial melt mass. As is evident from Fig. 6, these ejections occurred every 10-15 minutes, and they resulted in transient augmentation in the upwards heat flux to levels in the range of $1-3 \mathrm{MW} / \mathrm{m}^{2}$.

During disassembly, the concrete sidewalls were found to be eroded by as much as $10 \mathrm{~cm}$. Sidewall thermocouple data indicated that radial ablation was occurring as early as 50 minutes before onset of axial ablation. It is estimated that at onset of axial ablation, the total corium mass was $\sim 130 \mathrm{~kg}$, of which $23 \mathrm{wt} \%$ was concrete decomposition products from sidewall erosion. This large influx of concrete from the sidewalls during the preheat probably depressed the melt temperature to the extent that the $\mathrm{Zr}$ was not significantly melted. Thus, the actual M0 test conditions reflect a $100 \%$ oxidized PWR melt composition $\sim 23 \%$ diluted with concrete oxides run at 2 to 4 times prototypic decay heat level at 2 hours into the accident sequence.

Following the Scoping Test, the MACE facility was upgraded to allow larger scale tests of up to $75 \mathrm{~cm} \times 75 \mathrm{~cm}$ scale to be performed. The test section was constructed with refractory sidewalls $(\mathrm{MgO})$ rather than concrete to prevent early concrete dilution of the melt. The tungsten electrodes were recessed into the sidewalls to reduce the chances of crust anchoring on these surfaces. A new 0.56 MW power supply was installed, and an on-line gas mass spectrometer was added to the system. Test Mlb was subsequently conducted in a $50 \mathrm{~cm} \times 50 \mathrm{~cm}$ test section with a collapsed pool depth of $25 \mathrm{~cm}$. This test ran for six hours following onset of ablation. The experiment was terminated on the basis that most basemat thermocouples showed that the concrete temperature had stabilized, indicating that ablation had been arrested.

The M1b axial ablation front location, evaluated on the basis of the thermocouple measurements as well as the integrated noncondensable gas release $\left(\mathrm{CO} / \mathrm{CO}_{2}\right)$ from core-concrete interaction, is shown in Fig. 8. Water addition began when the basemat ablation depth had reached a depth of $5.0 \mathrm{~cm}$ (i.e., at 14.7 minutes). The view of the melt surface at this time indicated the presence of a perforated skeleton crust that had formed and attached to the test section sidewalls above the melt during the powder melting phase. The view below this crust revealed an intense interaction characteristic of MCCI's with metallic $\mathrm{Zr}$ present in the melt. [19] The presence of the skeleton crust did not inhibit water/melt contact. Other measurements

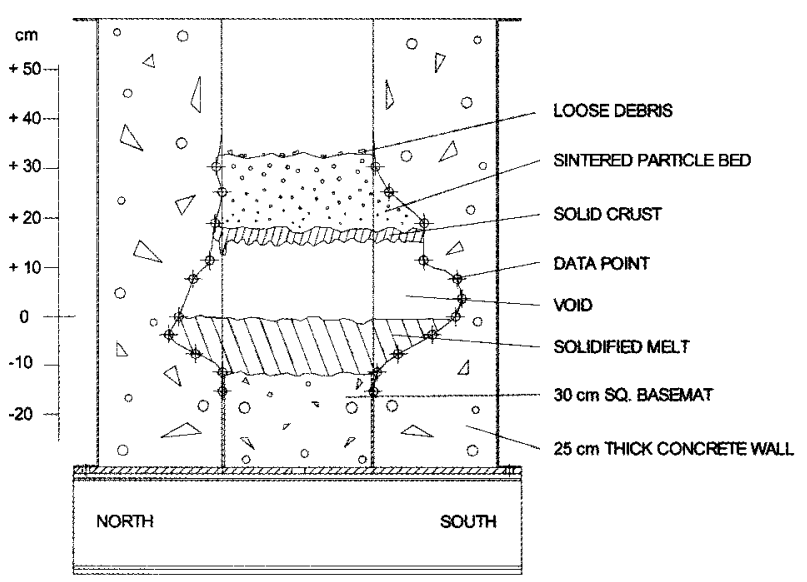

Fig. 7. M0 Posttest Debris Distribution

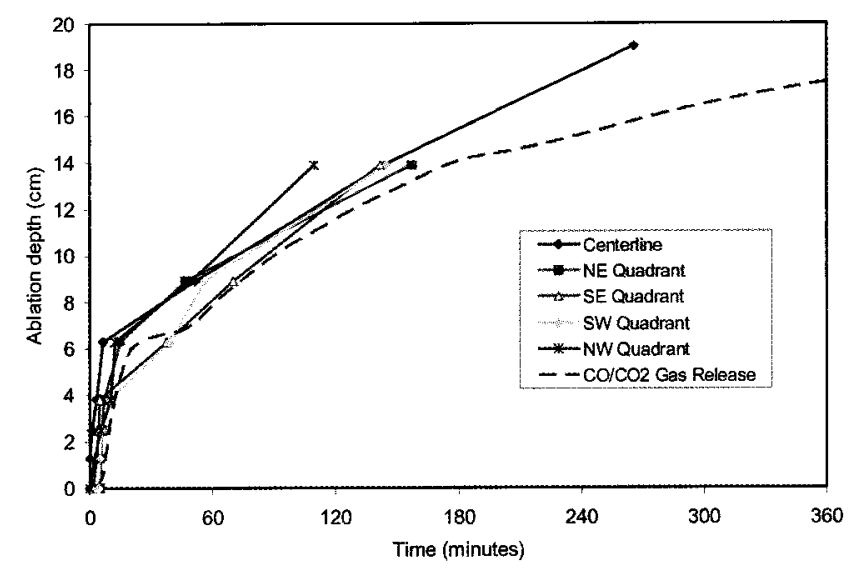

Fig. 8. M1b Axial Basemat Ablation Data 
indicated that the melt temperature at the time water was added was $\sim 2030^{\circ} \mathrm{C}$, and the melt sparging rate was $\sim$ $25 \mathrm{~cm} / \mathrm{sec}$.

The net melt/water heat flux for Test M1b is shown in Fig. 9, along with the DEH input power normalized with the test section planar area $0.25 \mathrm{~m}^{2}$ for comparison. For this test, the input power was at the target level of $350 \mathrm{~W} / \mathrm{kg}$ fuel at onset of basemat ablation. The melt/water heat flux data indicates that during the first 15 minutes of the interaction, a large cooling transient occured with the upwards heat flux peaking at nearly $4 \mathrm{MW} / \mathrm{m}^{2}$, which is consistent with the $\mathrm{M} 0$ result. The initial cooling transient resulted in a bulk melt temperature decline of $\sim 350^{\circ} \mathrm{C}$ (i.e., from 2030 to $1680{ }^{\circ} \mathrm{C}$ ) before stabilizing at $\sim 30$ minutes (Fig. 10). Given the melt mass of $\sim 500 \mathrm{~kg}$, then the bulk temperature decline of $350^{\circ} \mathrm{C}$ corresponds to $150 \mathrm{MJ}$ of upwards heat removal (assumed corium specific heat is $870 \mathrm{~J} / \mathrm{kg} \bullet \mathrm{K}$ ). However, the integrated upwards heat removal over the first 15 minutes of the

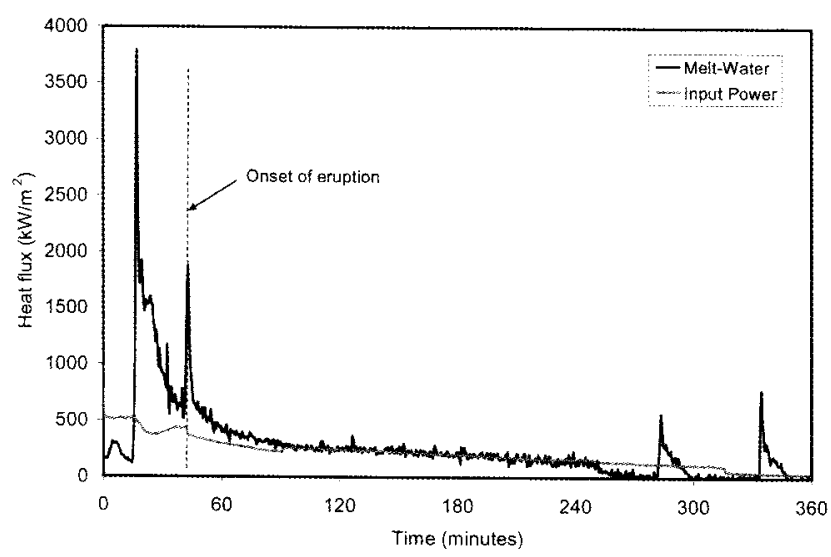

Fig. 9. Mlb Melt/water Heat Flux Data

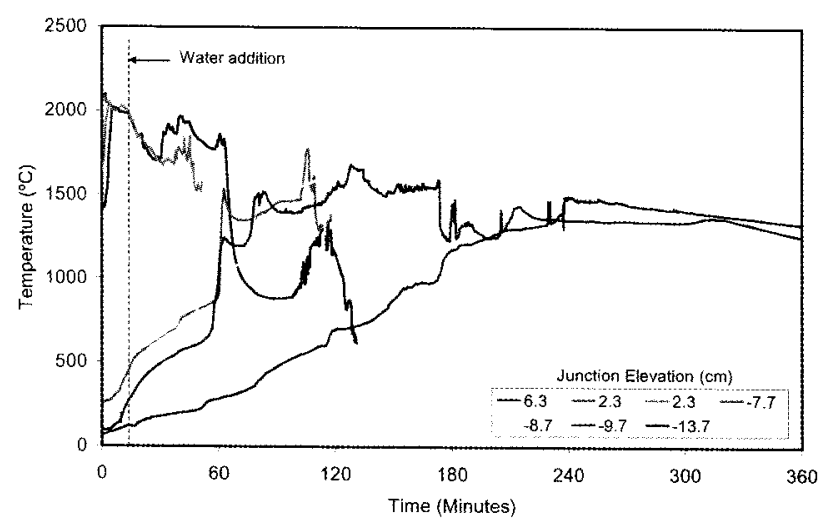

Fig. 10. M1b Melt Temperature Data interaction amounted to $\sim 350 \mathrm{MJ}$, which is $\sim 200 \mathrm{MJ}$ greater than that attributable to bulk heat removal alone. Thus, the data indicates that some amount of debris quenching at the melt/water interface must have occurred during the initial interaction. The change in the corium specific enthalpy during quench is estimated as $1.7 \mathrm{MJ} / \mathrm{kg}$ for the Mlb melt composition. The energy balance deficit of $200 \mathrm{MJ}$ can thus be accounted for by complete quench of $117 \mathrm{~kg}$ of corium. Posttest analyses indicated that the mass of the skeleton crust amounted to $26 \mathrm{~kg}$, which leaves $\sim 90 \mathrm{~kg}$ of material which could have quenched and stabilized during the initial interaction. For an assumed crust density of $6000 \mathrm{~kg} / \mathrm{m}^{3}$, the $90 \mathrm{~kg}$ of core material would amount to a crust thickness of $\sim 6 \mathrm{~cm}$ in the $50 \mathrm{~cm} \times 50 \mathrm{~cm}$ test section. The posttest debris examination (Fig. 11) indicates that this crust thickness estimate is in reasonable agreement with the posttest measurements of the bridge crust thickness.

Other test data indicates that the initial melt/water interaction had a significant stabilizing effect on the MCCI. The ablation data (Fig. 8) indicates that the upwards heat transfer caused a concurrent reduction in the ablation rate. In particular, the ablation rate at onset of water addition was $\sim 3.2 \mathrm{~mm} / \mathrm{min}$ based on the basemat noncondensable gas release rate. During the first 15 minutes of the melt/water interaction, the ablation rate steadily declined to a level of $\sim 0.2 \mathrm{~mm} / \mathrm{min}$ based on the same data. However, over the time interval 30-60 minutes, the ablation rate gradually increased back to a peak postwater addition level of $\sim 1 \mathrm{~mm} / \mathrm{min}$. During this same time interval, the baseline melt/water heat flux declined rapidly to a level of $\sim 400 \mathrm{~kW} / \mathrm{m}^{2}$ at 60 minutes. The thermocouple data indicates that the melt temperature stabilized during this period. All of these events are

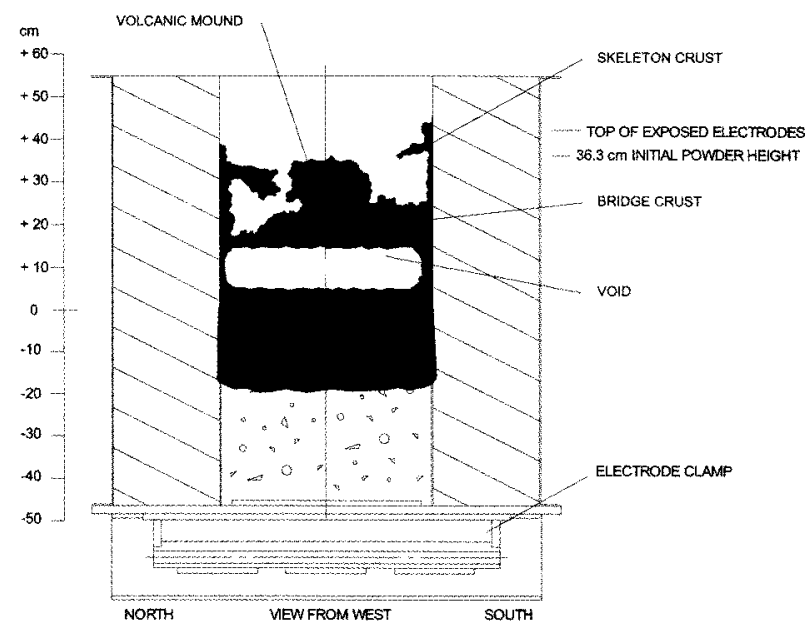

Fig. 11. M1b Posttest Debris Configuration 
consistent with the formation of an interfacial crust. Assuming a crust thermal conductivity of $\sim 1 \mathrm{~W} / \mathrm{m} \cdot \mathrm{K}$ and a temperature drop of $\sim 1000^{\circ} \mathrm{C}$ across the crust (i.e., upper surface in nucleate boiling and lower surface near corium solidus of $\sim 1100^{\circ} \mathrm{C}$ ), then the crust thickness to supply the observed heat load of $400 \mathrm{~kW} / \mathrm{m}^{2}$ to the water is found to be $\sim 3 \mathrm{~mm}$ assuming that the heat transfer is conduction limited. This crust thickness is more than an order of magnitude less than the actual thickness of $\sim 6$ $\mathrm{cm}$ based on both analysis and posttest examinations. This calculation thus indicates that the M1b crust was most likely permeable to water ingression and that the temperature drop across the crust occurred across a thin thermal boundary layer located at the crust bottom surface.

Unfortunately, the crust that formed during the initial interaction also anchored to the test section sidewalls in this increased-scale test, eventually leading to an intervening gap $\sim 9 \mathrm{~cm}$ high as the MCCI continued downwards (Fig. 11). As discussed earlier, gap formation is believed to adversely affect efficient heat transfer mechanisms that occur when the melt is in contact with the crust. For this test, separation is thought to have occurred at $\sim 50$ minutes, as evidenced by the decline in melt water heat flux and the resurgence of basemat ablation after this time.

As in the Scoping Test, Test Mlb provided evidence of periodic ejections of molten corium. A large melt eruption was observed on video at $\sim 42$ minutes which led to a significant transient increase in the upwards heat flux up to $\sim 1.7 \mathrm{MW} / \mathrm{m}^{2}$. The heat flux data also indicates that two minor eruptions may have occurred late in the test sequence (i.e., at 285 and 338 minutes). However, these eruptions were not evident on the melt surface video. The location of the volcano in M1b was near the center of the test section. The mass of ejected material amounted to $19.1 \mathrm{~kg}$, which is only $\sim 4 \%$ of the initial melt mass. This fraction is significantly less than that for the Scoping Test (i.e., $20 \%$ ). However, the volcano grew axially to the extent that it contacted (and bonded with) the underside of the skeleton crust. Thus, the possibility exists that this contact could have sealed the vent passageway(s), thereby suppressing further eruptions.

After the first 60 minutes, the input power (at constant voltage), melt temperature, and basemat ablation rate steadily declined over the balance of the test. This trend is probably due to the fact that the upwards heat transfer rate remained significant in comparison to the input power (Fig. 9). The result was that after six hours of operation with water over the melt, the melt temperature had fallen to near the concrete liquidus of $\sim 1250{ }^{\circ} \mathrm{C}$.

During disassembly, one electrode sidewall was found to be significantly eroded. Sidewall temperature measurements indicated that this interaction occurred during the $\sim 6$ hour corium preheat, and that the interaction essentially stopped once water was added. It is estimated that at onset of ablation, the total corium mass was $\sim 480 \mathrm{~kg}$, of which $\sim 63 \mathrm{~kg}$ was $\mathrm{MgO}$ from sidewall erosion. Thus, the actual M1b test conditions reflect a $70 \%$ oxidized PWR melt composition $\sim 20 \%$ diluted with concrete oxides run at prototypic decay heat level at two hours into the accident sequence.

Following M1b, the overall experiment approach for MACE was reexamined. In particular, the facility was redesigned to accommodate the largest possible test section in order to minimize the chances of crust anchoring to the test section sidewalls, as occurred in both previous tests. As shown in Table 3, this effort resulted in a test section featuring an internal cross section of $120 \mathrm{~cm} \times$ $120 \mathrm{~cm}$. The corresponding initial melt mass was specified as $1950 \mathrm{~kg}$, yielding an initial collapsed melt depth of 20 $\mathrm{cm}$. The test section design was also upgraded to include a $\mathrm{UO}_{2}$ pellet liner between the corium charge and the $\mathrm{MgO}$ sidewalls. The liner was added to eliminate reactions between the corium and the sidewalls, as occurred in M1b. Finally, extensive laboratory testing was carried out to develop an exothermic chemical mixture capable of producing a prototypic core melt composition over a short timescale (i.e., $\sim 30$ seconds).

Test M3b ran for six hours following onset of ablation. The experiment was terminated on the basis that virtually all melt temperature thermocouples showed that the temperature had fallen below the concrete solidus of $1100^{\circ} \mathrm{C}$. The ablation front location data is shown in Fig. 12. Water addition began when the ablation depth had reached the target depth of $1.3 \mathrm{~cm}$ (i.e., at 52 minutes). Other measurements indicated that the melt temperature at the time water was added was $\sim 1870^{\circ} \mathrm{C}$, and the melt sparging rate was $\sim 12 \mathrm{~cm} / \mathrm{sec}$.

The net melt/water heat flux for M3b is shown in Fig. 13 , along with the input power normalized with the test

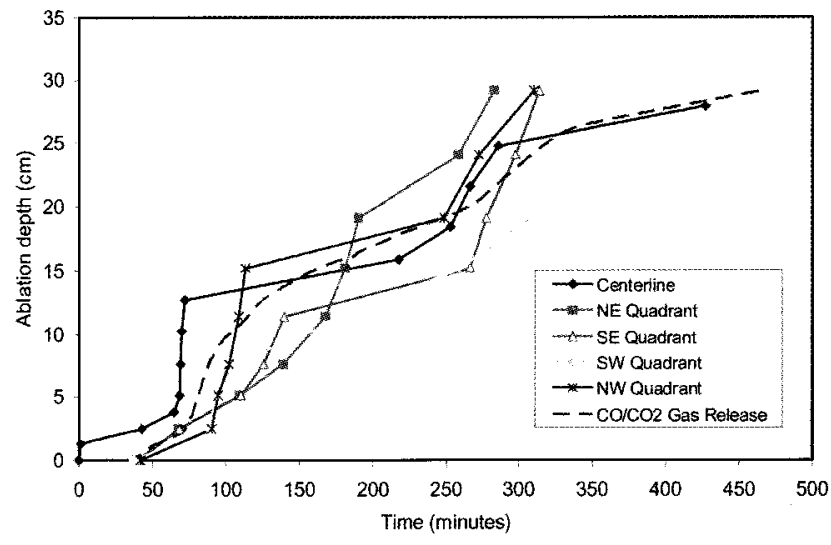

Fig. 12. M3b Axial Basemat Ablation Data 
section planar area $1.44 \mathrm{~m}^{2}$ for comparison. Note that the input power was at the target level of $300 \mathrm{~W} / \mathrm{kg}$ fuel at the time of water addition (viz. $\sim 250 \mathrm{~kW} / \mathrm{m}^{2}$ input heat flux). However, target power could not always be met since the $0.56 \mathrm{MW}$ power supply was slightly undersized for this test scale. The data indicates that during the first 20 minutes of the interaction, a large cooling transient occurred with the initial upwards heat flux peaking at nearly $1.8 \mathrm{MW} / \mathrm{m}^{2}$. This peak is less than the $4 \mathrm{MW} / \mathrm{m}^{2}$ level reached for the M0 and Mlb tests. The reduced initial cooling rate is attributable to the fact that the melt temperature for M3b was lower (Fig. 14), and also that the corium contained less concrete as an initial constituent (i.e., $\sim 8 \mathrm{wt} \%$ ) in comparison to M0 and M1b. The lower melt temperature, in conjunction with the reduced presence of concrete oxides, resulted in a

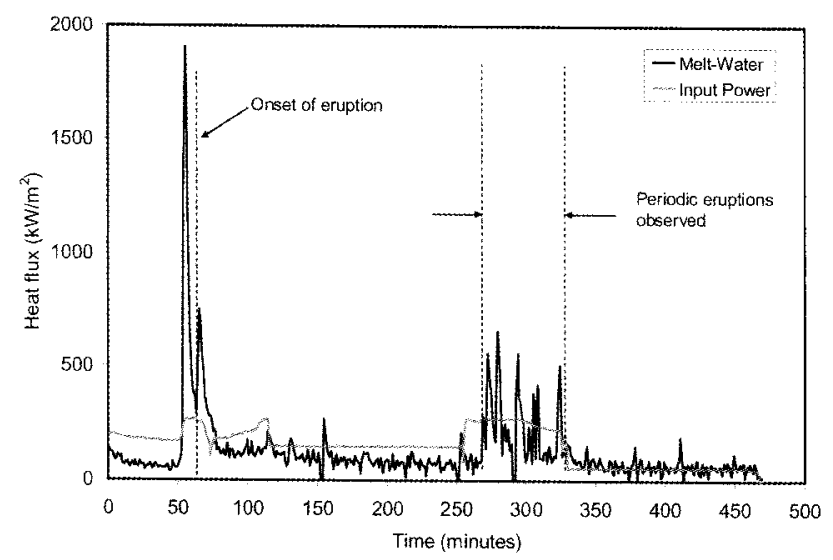

Fig. 13. M3b Melt/water Heat Flux Data

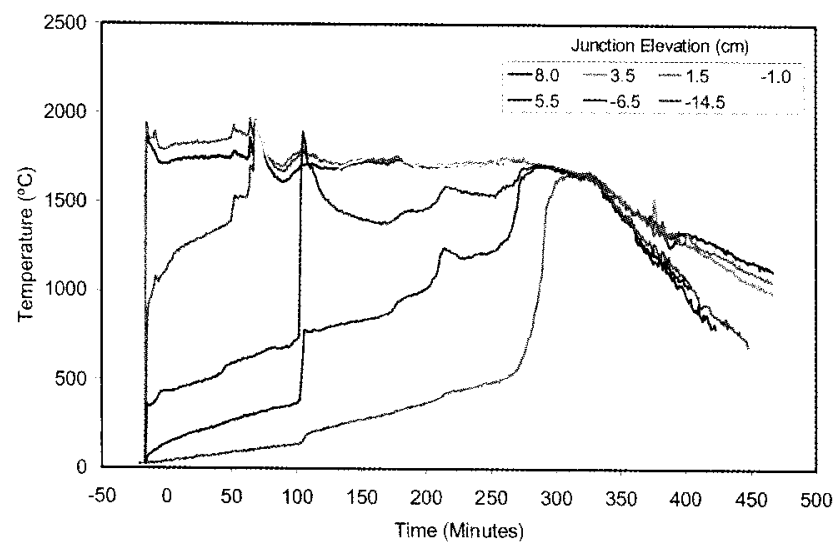

Fig. 14. M3b Melt Temperature Data more viscous melt which underwent a less effective bulk transient compared to the other tests.

Although there are fluctuations, the data generally indicates that the melt temperature did not change significantly following the initial 20 minute cooling transient that resulted in $\sim 1.1$ GJ of upwards heat removal. The lack of a bulk temperature decrease indicates that the heat removal was again dominated by an interfacial freezing process, as opposed to convective cooling of the entire melt pool. The melt specific enthalpy change upon quench is estimated as $1.1 \mathrm{MJ} / \mathrm{kg}$ for the M3b melt composition. The integrated heat removal of $1.1 \mathrm{GJ}$ to the overlying water during the first 20 minutes of the interaction is thus consistent with quench of $\sim 1000 \mathrm{~kg}$ of core material. This material amounts to $\sim 51 \%$ of the initial melt mass of $1950 \mathrm{~kg}$. The posttest debris configuration is shown in Fig. 15. As is evident, the net mass of the bridge crust was found to be $1050 \mathrm{~kg}$, which agrees within $5 \%$ of the quenched debris mass predicted on the basis of the energy deposition in the quench system. Other test data (i.e., power supply response) is consistent with quench of $\sim 1 / 2$ the initial melt mass during the first 20 minutes of the test. Posttest measurements also indicate that this thick bridge crust was permeable to both gas and water flows. Finally, debris temperature measurements logged during the posttest cooldown indicate that water passed through the crust and quenched the underlying debris over the time interval 550-680 minutes after onset of ablation (or 80-210 minutes after the test was terminated). Thus, these diverse sources of information indicate that a significant cooling transient occurred over the first 20 minutes of M3b which rendered $\sim 1 / 2$ the initial melt mass quenched and coolable by virtue of water ingression into a growing crust.

As further indicated in Fig. 15, the crust which formed

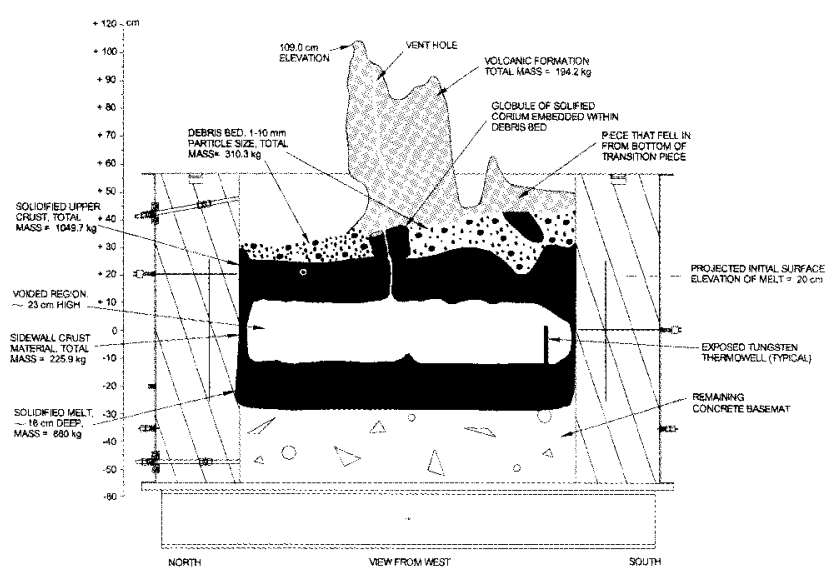

Fig. 15. M3b Posttest Debris Configuration 
during the initial interaction also anchored to the sidewalls, eventually leading to the formation of an intervening gap $\sim 23 \mathrm{~cm}$ high as the MCCI continued downwards. Separation is believed to have occurred at $\sim 72$ minutes, as evidenced by the steep decline in melt/water heat flux and the resurgence of basemat ablation after this time. Over the next two hours of the experiment, the melt temperature and ablation rate approached steady state conditions, while the melt/water heat flux declined steadily. The reduction in upwards heat transfer has been attributed to increasing radiation heat transfer loss to the test section sidewalls as the melt receded from the suspended crust due to concrete densification upon melting.

As in the previous tests, M3b provided evidence of periodic ejections of molten corium. An eruption was observed on video during the initial stage of the interaction which led to a significant increase in the upwards heat flux to $\sim 700 \mathrm{~kW} / \mathrm{m}^{2}$. Over the time interval of $252-328$ minutes, the input power was increased back to the initial target level of $390 \mathrm{~kW}$. Following the power increase, periodic eruptions were observed until the power was again reduced at 328 minutes. As shown in Fig. 13, these eruptions resulted in increases in the upwards heat flux to levels as high $700 \mathrm{~kW} / \mathrm{m}^{2}$. The posttest debris examinations indicated that the ejected material was quenched in the form of a large volcanic formation overlying a debris bed which was composed of spherical particles. The location of the volcano was near the center of the test section. The mass of the ejected material amounted to $505 \mathrm{~kg}$, of which $310 \mathrm{~kg}$ was located in the particle bed, while the balance (i.e., $195 \mathrm{~kg}$ ) was in lava formations. The $505 \mathrm{~kg}$ of ejected material amounts to $\sim 26 \%$ of the initial melt mass. This fraction is slightly larger than that for test M0 (i.e., $20 \%$ ). A photograph showing the debris upper surface is provided in Fig. 16.

During the eruption phase of $\mathrm{M} 3 \mathrm{~b}$, the input power

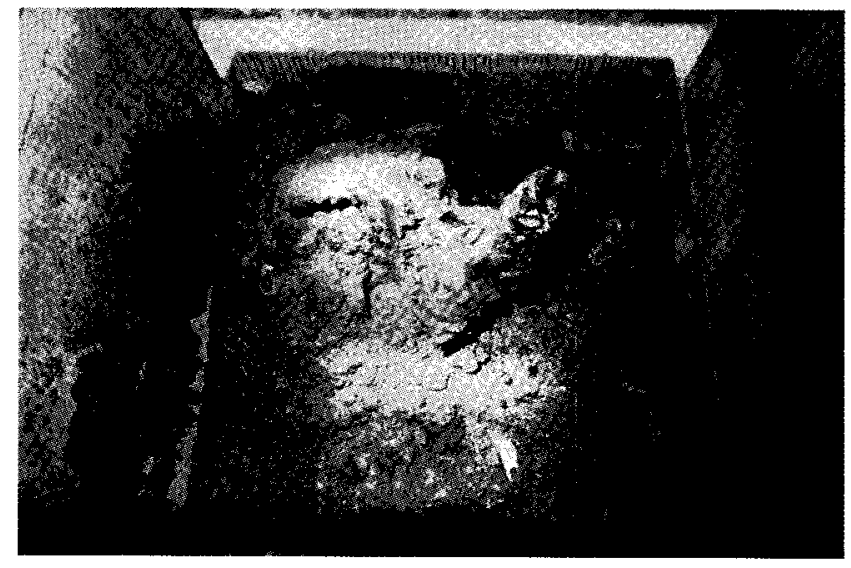

Fig. 16. Upper Surface of the M3b Posttest Debris was maintained approximately constant at the initial target level of $390 \mathrm{~kW}$. As a result, the specific power density in the remaining melt steadily climbed from $500 \mathrm{~W} / \mathrm{kg} \mathrm{UO} \mathrm{UO}_{2}$ after the power increase to $\sim 1400 \mathrm{~W} / \mathrm{kg}$ $\mathrm{UO}_{2}$ at the end of the increased power period. The increase is attributable to loss of material from the melt zone (at constant power) due to the eruptions. The specific power density at the end of the eruptive phase is noted to be $\sim 5$ times the target power density of 300 $\mathrm{W} / \mathrm{kg} \mathrm{UO}$ for this test.

After the power reduction at 328 minutes, the melt temperature steadily declined to below the concrete solidus of $\sim 1100^{\circ} \mathrm{C}$ at 470 minutes (Fig. 14). This trend is most likely attributable to the fact that the upwards heat transfer rate approximately balanced the input power during this time (Fig. 13). The test was eventually terminated on the basis that the bulk melt temperature had fallen below the concrete solidus.

Posttest examinations further revealed that $\sim 1 / 3$ of the bridge crust failed and relocated downwards at least once. This conclusion is based on the fact that a large fracture ridge was found in the crust which roughly spanned two opposing corners of the test section (Fig. 17). The crust on the side of the ridge which had relocated was highly cracked, and the surface elevations in this area were below the initial collapsed melt height. Thus, although the important objective of maintaining a floating crust was not met in this increased scale test, the $\mathrm{M} 3 \mathrm{~b}$ posttest debris configuration nonetheless suggests that a floating crust boundary condition is the expected situation at plant scale.

During disassembly, the $\mathrm{MgO}$ sidewalls were found to be in very good condition, indicating that the $\mathrm{UO}_{2}$ liner had functioned properly insofar as protecting the test section sidewalls. Thus, during the first 4 hours of

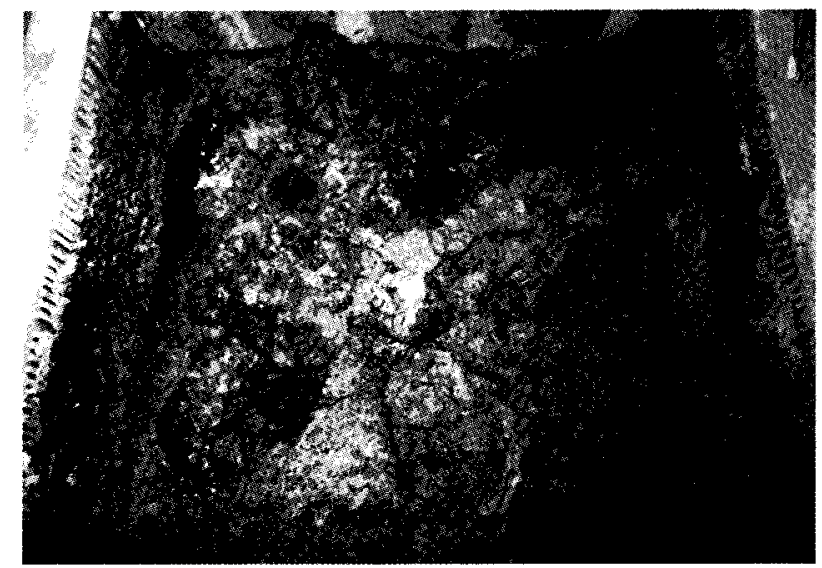

Fig. 17. Photograph Showing M3b Fractured Bridge Crust after Particle Bed Removal. 
$\mathrm{M} 3 \mathrm{~b}$, the test conditions reflect a $100 \%$ oxidized core melt composition initially diluted with $\sim 8 \%$ concrete oxides run at prototypic decay heat level at two hours into the accident sequence. During the elevated power period from 252-328 minutes, the power density varied from 2 - 5 times the target level.

Due to the fact that an anchored crust formed in M3b, the program's Technical Advisory Committee concluded that the increased costs associated with conducting tests at the $120 \mathrm{~cm} \times 120 \mathrm{~cm}$ scale was not warranted, and therefore the decision was made to return to the smaller $50 \mathrm{~cm} \times 50 \mathrm{~cm}$ test section. Furthermore, all previous tests were conducted with LCS concrete, and therefore the decision was made to conduct a test with a siliceous concrete basemat to round out the test matrix. This test, denoted M4, was conducted with a system very similar to that used for M1b, with the exception that an exothermic chemical mixture was used to generate the melt as opposed to DEH. The mixture was reformulated to contain $8.5 \mathrm{wt} \%$ calcined siliceous concrete, as opposed to calcined LCS concrete used for the M1b and M3b mixtures. As shown in Table 3, Test M4 was conducted with a 480 $\mathrm{kg}$ corium mass, yielding an initial collapsed melt depth of $30 \mathrm{~cm}$ in the $50 \mathrm{~cm} \times 50 \mathrm{~cm}$ test section. The test section design retained the use of a $\mathrm{UO}_{2}$ pellet liner to protect the $\mathrm{MgO}$ sidewalls. Final important additions to the design were two insertable "crust busters" which were to be used to dislodge a bridge crust should one develop during the test.

M4 ran for 4 hours following onset of ablation, and the test was terminated on the basis that the maximum permissible axial ablation depth of $31 \mathrm{~cm}$ had been reached. The ablation data is provided in Fig. 18. Water addition began when the ablation depth reached $3.8 \mathrm{~cm}$ (i.e., at 22.8 minutes). The melt temperature was $\sim 1930^{\circ} \mathrm{C}$ at the time of flooding, and the melt sparging rate was $15 \mathrm{~cm} / \mathrm{sec}$.

The input power was at the target level of $300 \mathrm{~W} / \mathrm{kg}$

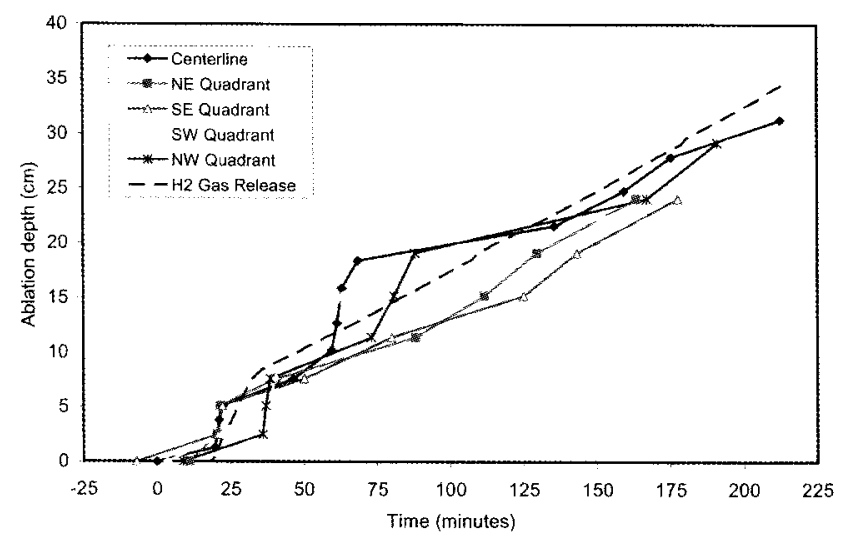

Fig. 18. M4 Axial Basemat Ablation Data
$\mathrm{UO}_{2}$ when water was added. The heat flux data (Fig. 19) indicates that during the first 20 minutes of the interaction, a large cooling transient occurred with the initial upwards heat flux peaking in excess of $4 \mathrm{MW} / \mathrm{m}^{2}$. The overall shape and magnitude of this transient is quite similar to that observed in the other tests with LCS concrete.

Melt temperature measurements (Fig. 20) were only obtained in the lower elevations of the debris (i.e., $<15 \mathrm{~cm}$ ), since posttest examinations indicated that all thermocouples at the higher elevations had failed at some point in the experiment. There are fluctuations, but the data generally indicate that the melt temperature declined by no more than $100^{\circ} \mathrm{C}$ following a 20 minute cooling transient that resulted in $\sim 340 \mathrm{MJ}$ of upwards heat removal. The lack of a significant bulk temperature decrease again suggests that the heat removal was dominated by an interfacial freezing process. Given the melt composition, then the corium specific enthalpy change upon quench is found to be $\sim 1.1 \mathrm{MJ} / \mathrm{kg}$. The integrated heat removal of $340 \mathrm{MJ}$

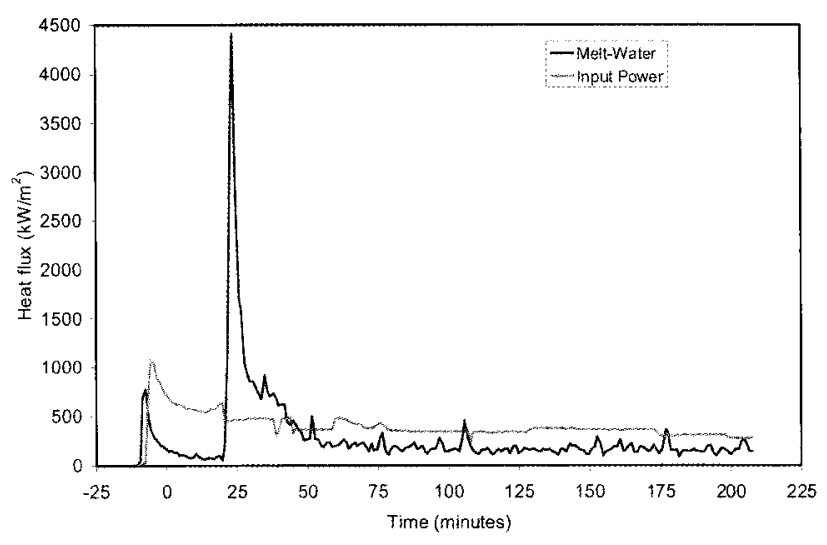

Fig. 19. M4 Melt/water Heat Flux Data

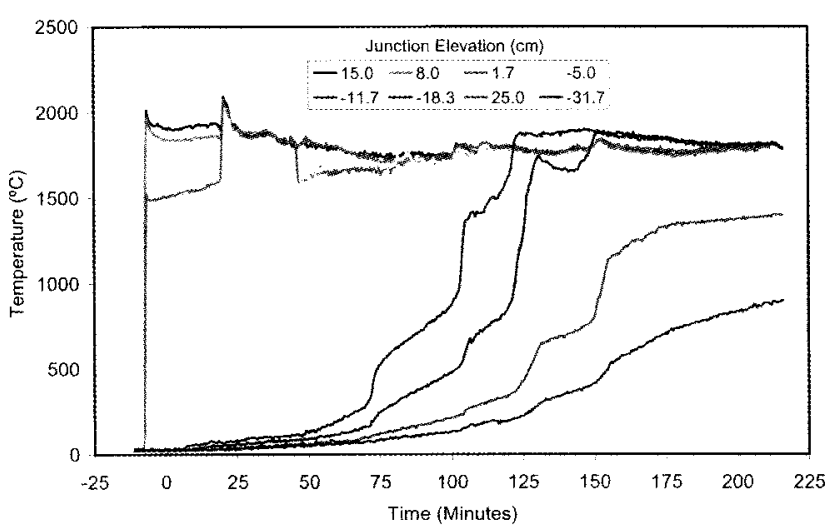

Fig. 20. M4 Melt Temperature Data 
over the first 20 minutes of the interaction is thus consistent with complete quench of $310 \mathrm{~kg}$ of core material. This mass of material amounts to $\sim 65 \%$ of the initial charge mass of $480 \mathrm{~kg}$. The M4 posttest debris configuration is shown in Fig. 21. As indicated, the mass of the bridge crust was $82 \mathrm{~kg}$, while the mass of the sidewall crust material above the bridge crust amounted to $225 \mathrm{~kg}$. The total mass of frozen material located above the voided region thus amounted to $307 \mathrm{~kg}$, which agrees within a few \% of that predicted on the basis of the energy deposition in the quench system. The melt surface video indicated that the melt-water interaction was quite chaotic during the first several minutes following cavity flooding. Thus, the visual information and the magnitude of the energy removal both indicate that a large percentage of the sidewall crust material was probably deposited during this stage.

Sidewall plateout of crust material is not expected to be a significant contributor to coolability at plant scale. However, the relatively thick $(\sim 6 \mathrm{~cm})$ bridge crust that formed is similar to that in Tests M1b and M3b. Moreover, posttest measurements indicated that this crust was permeable to water flow. Another interesting finding is that the bridge crust contained a large hole with an area of $\sim 15 \mathrm{~cm}^{2}$. The data indicates that this hole most likely formed $\sim 12$ minutes after water was added to the test section (i.e., at 35 minutes), and that water was able to flow down through this hole to occupy the intervening gap for the balance of the test. No evidence of the broken crust piece(s) was found in the voided region, indicating that the material was absorbed into the melt. A significant ancillary question is the relative effect of this crust failure

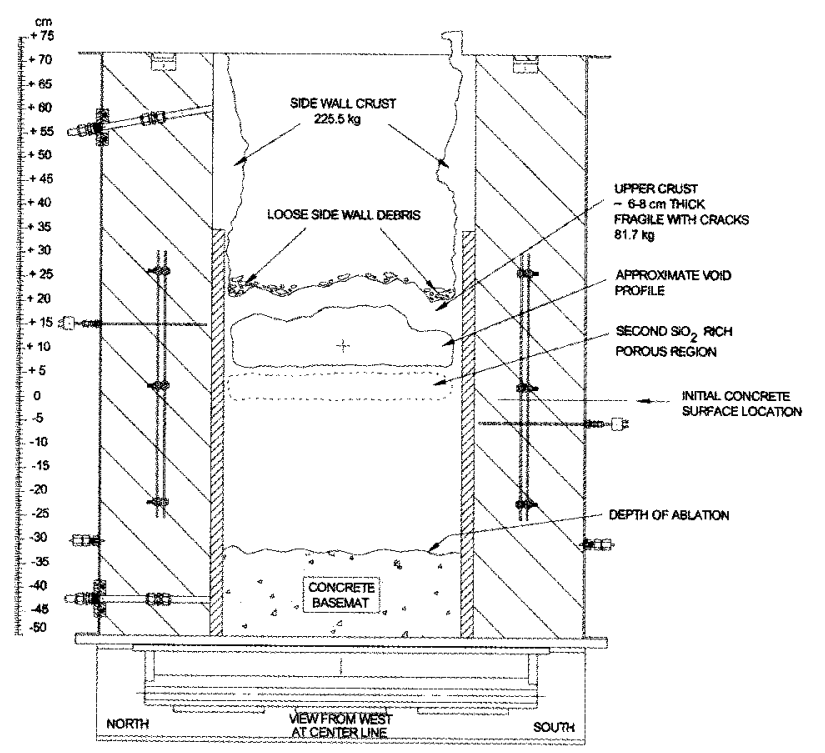

Fig. 21. M4 Posttest Debris Configuration on the upwards heat flux. A small increase in upwards heat flux is noted at $\sim 35$ minutes from $\sim 700 \mathrm{~kW} / \mathrm{m}^{2}$ up to $\sim 900 \mathrm{~kW} / \mathrm{m}^{2}$, which is near the critical heat flux (CHF) limit of $\sim 1 \mathrm{MW} / \mathrm{m}^{2}$ at atmospheric pressure. This increase is not representative of that which would occur during bulk cooling. The likely reason is that the melt sparging rate had fallen below the critical valve to preclude stable crust formation. Thus, the water most likely flooded the intervening gap and formed a second crust almost immediately, which would account for the slight heat flux escalation up to near CHF, as opposed to large areaenhanced augmentation of upwards heat flux as occurs without an intervening stable crust. One encouraging note is that the insertable crust busters were not used until much later in the test sequence (i.e., 95 minutes). These probes, which impacted the crust at different locations from where the hole was located, were not successful in penetrating the crust. Thus, the crust breach event observed in Test M4 occurred by natural means.

Following breach and the formation of the new crust below, the heat flux gradually decreased to a steady state level of $\sim 160 \mathrm{~kW} / \mathrm{m}^{2}$ where it remained for the balance of the test. The MCCI continued its downward migration. No evidence of eruptions or subsequent crust breach events was found in the voided region beneath the bridge crust. Moreover, sidewall thermocouple and melt/water heat flux data do not indicate that there was any significant water ingression into the remaining melt pool. Examination of the underlying crust indicated that it was very high in $\mathrm{SiO}_{2}$, as may be expected for this type of concrete. As shown in Fig. 21, the ongoing MCCI led to the development of an intervening gap $\sim 10 \mathrm{~cm}$ high by the end of the test. The experiment was terminated at 215 minutes on the basis that the maximum permissible ablation depth had been reached.

During disassembly, the $\mathrm{MgO}$ sidewalls were found to be in very good condition. Thus, the test conditions for M4 reflected a $100 \%$ oxidized core melt composition initially diluted with $\sim 8 \%$ concrete oxides run at prototypic decay heat level at two hours into the accident sequence.

\subsubsection{OECD/MCCI Experiments}

The experiment approach in the MACE program was to attempt to resolve the debris coolabilty issue through large, integral-type demonstration tests. Although the tests provided unique insights into heat transfer mechanisms that can contribute to long term cooling, the results did not demonstrate definitely that the melt could always be quenched. This was due to the fact that the crust anchored to the test section sidewalls, leading to melt/crust separation, even at the largest test section lateral span of $1.20 \mathrm{~m}$. On this basis, the MCCI program was initiated to provide both confirmatory evidence and test data to support model development activities for coolability mechanisms identified in MACE integral tests. The first phase of this project has been completed, [13] while the second phase 
is ongoing. Principal results of coolability-related experiments from the first phase of the project are summarized herein.

Two types of separate effects tests were conceived to investigate the melt cooling mechanisms discussed in Table 1. The first of these, the Small Scale Water Ingression and Crust Strength (SSWICS) tests, [13,14-16] provided data on the water ingression mechanism. In addition, crust strength data obtained as part of the posttest examinations was used to validate the concept of sustained melt/crust contact due to crust instability in the typical cavity span of most plants. [16]

Aside from SSWICS, The Melt Eruption Tests (MET) were intended to provide data on melt eruption processes under well-controlled experiment conditions. Using an apparatus similar to the MACE $50 \mathrm{~cm} \times 50 \mathrm{~cm}$ test section, the experiments were designed with an inert basemat with remotely controlled gas sparging, since this is the most important parameter determining the melt entrainment rate. [20] Two MET tests were originally planned in the MCCI program. MET-1 was conducted with a $350 \mathrm{~kg}$ core melt mass containing $23 \mathrm{wt} \%$ siliceous concrete to investigate eruption processes late in the accident sequence. Unfortunately, this test was not operationally successful due to melt breach of the test section during the corium preheat phase. On this basis, program efforts were refocused on the conduct of a third Core-Concrete Interaction (CCI) test as opposed to a second melt eruption test. Aside from the operational difficulties encountered during MET-1, this decision was motivated by the fact that integral-type melt eruption data was obtained during the CCI tests that were conducted as the third major element of the test program.

The principal objective of the CCI tests was to provide data on the axial/lateral power split during dry coreconcrete interaction, since there was a lack of reactor material test data that could be used for code validation at the time the project was initiated. [21] To help bridge this gap, integral tests replicating as close as possible the expected plant-scale conditions were conducted to provide a database that could be used for validation. [11-13] To increase the information gathered from these tests, the core-concrete interaction was flooded from above after a pre-defined concrete ablation depth was reached to provide debris coolability data under the conditions of late phase flooding.

The SSWICS tests [14-16] addressed the following questions related to water ingression and crust breach: i) to what extent does water ingress into core material to augment what would otherwise be an inefficient, conduction-limited cooling process, and ii) what is the mechanical strength of this solidifying core material and would it be mechanically stable if the crust attached to the reactor cavity walls during the quench process? A total of seven tests were carried out in two complimentary test facilities to address these questions. Test characteristics are summarized in Table 4.

Water ingression was studied by measuring the cooling rate of a melt pool in an inert crucible with no internal heating. Under these conditions, the water ingression rate could be determined by comparing the actual corium cooling rate with analytical solutions for the conduction-

Table 4. Specifications for SSWICS Tests

\begin{tabular}{|c|c|c|c|c|c|c|c|}
\hline \multirow{2}{*}{ Parameter } & \multicolumn{7}{|c|}{ Test Number } \\
\hline & 1 & 2 & 3 & 4 & 5 & 6 & 7 \\
\hline Test section ID (cm) & 30.5 & 30.5 & 30.5 & 30.5 & 30.5 & 30.5 & 30.5 \\
\hline $\begin{array}{l}\text { Melt composition } \\
\text { (wt } \% \mathrm{UO}_{2} / \mathrm{ZrO}_{2} / \mathrm{Cr} / \text { Concrete) }\end{array}$ & $61 / 25 / 6 / 8$ & $61 / 25 / 6 / 8$ & $61 / 25 / 6 / 8$ & $48 / 20 / 9 / 23$ & $56 / 23 / 7 / 14$ & $56 / 23 / 6 / 14$ & $64 / 26 / 6 / 4$ \\
\hline Concrete type & $\operatorname{LCS}^{a}$ & SIL $^{b}$ & LCS & LCS & LCS & SIL & LCS \\
\hline Melt mass $(\mathrm{kg})$ & 75 & 75 & 75 & 60 & 68 & 68 & 80 \\
\hline Melt depth $(\mathrm{cm})$ & 15 & 15 & 15 & 15 & 15 & 15 & 15 \\
\hline Initial Melt Temperature $\left({ }^{\circ} \mathrm{C}\right)$ & -2300 & $\sim 2100$ & -2100 & $\sim 2100$ & $\sim 2100$ & $\sim 1950$ & -2100 \\
\hline Basemat type & Inert & Inert & Inert & Inert & Inert & Inert & Inert \\
\hline System pressure (bar) & 1 & 1 & 4 & 4 & 4 & 1 & 4 \\
\hline Water injection flowrate (lpm) & 4 & 4 & 12 & 13 & 6 & 14 & 13 \\
\hline Water injected (liters) & 33 & 39 & 34 & 40 & 61 & 47 & 40 \\
\hline
\end{tabular}

denotes Limestone/Common Sand concrete;

${ }^{b}$ denotes Siliceous concrete. 


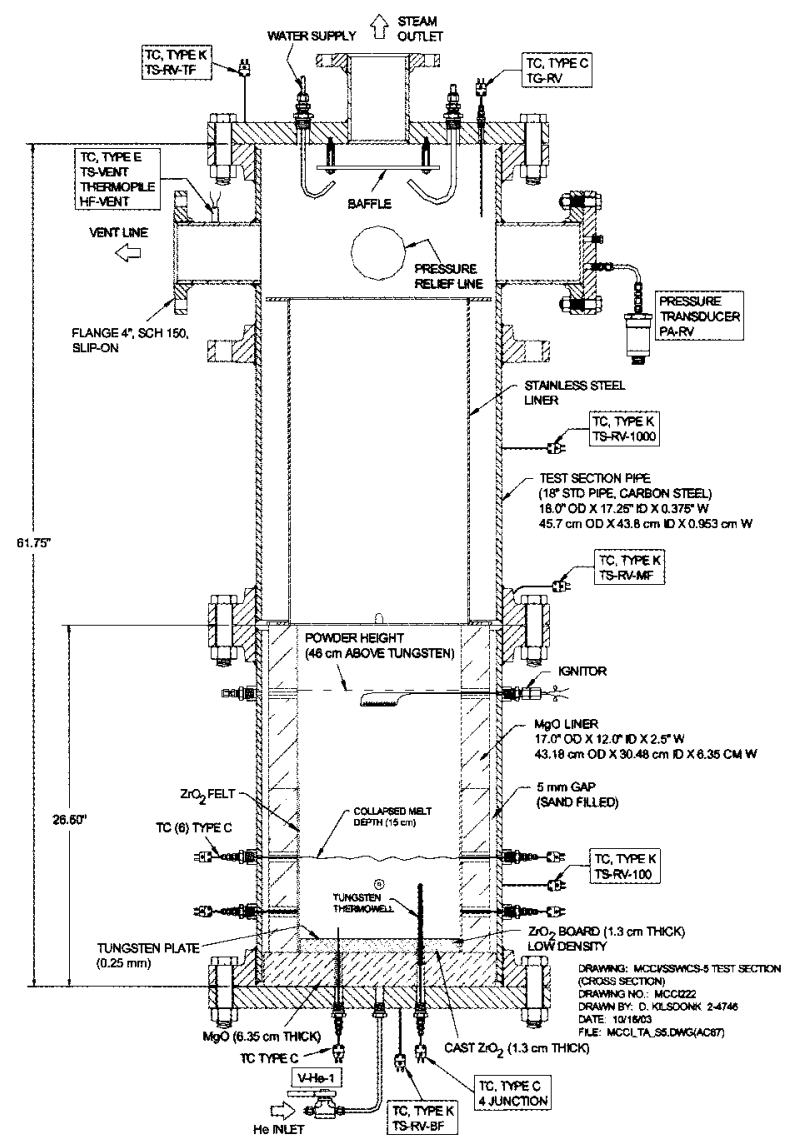

Fig. 22. Side View of SSWICS Reaction Vessel limited cooling of solids. In particular, a plateau in the cooling rate is expected to occur above the conductionlimited solution when equilibrium is achieved in the percolation of liquid down to the quench front and the return flow of steam through the network of cracks within the crust. Such a plateau is often referred to as the "dryout" heat flux.

The SSWICS reaction vessel (Fig. 22) consisted of a $67 \mathrm{~cm}$ long, $46 \mathrm{~cm}$ outer diameter carbon steel pipe. The pipe was insulated from the melt by a $6 \mathrm{~cm}$ thick layer of cast $\mathrm{MgO}$. This geometry produced a $30 \mathrm{~cm}$-diameter melt pool. The melt depth in all tests was fixed at $15 \mathrm{~cm}$; the corresponding melt mass to achieve this depth ranged from $60-80 \mathrm{~kg}$, depending upon the melt density for the given composition. As in the MACE program, the corium melt was produced with an exothermic chemical mixture.

Following each test, the corium ingots were removed for additional characterization. To provide further information on the crust permeabilities, water percolation tests were conducted. This data was used to formulate additional estimates of the crust dryout limits based on

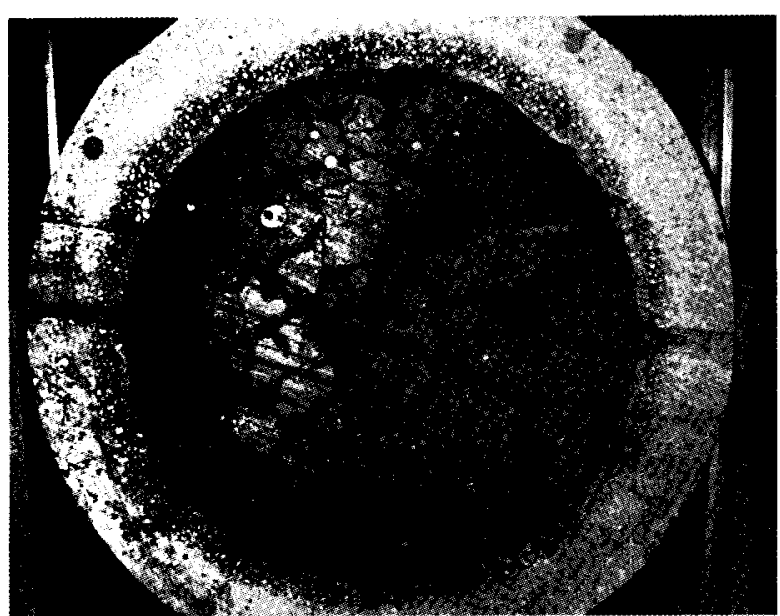

Fig. 23. Sectioned SSWICS Ingot Showing Crack Structure

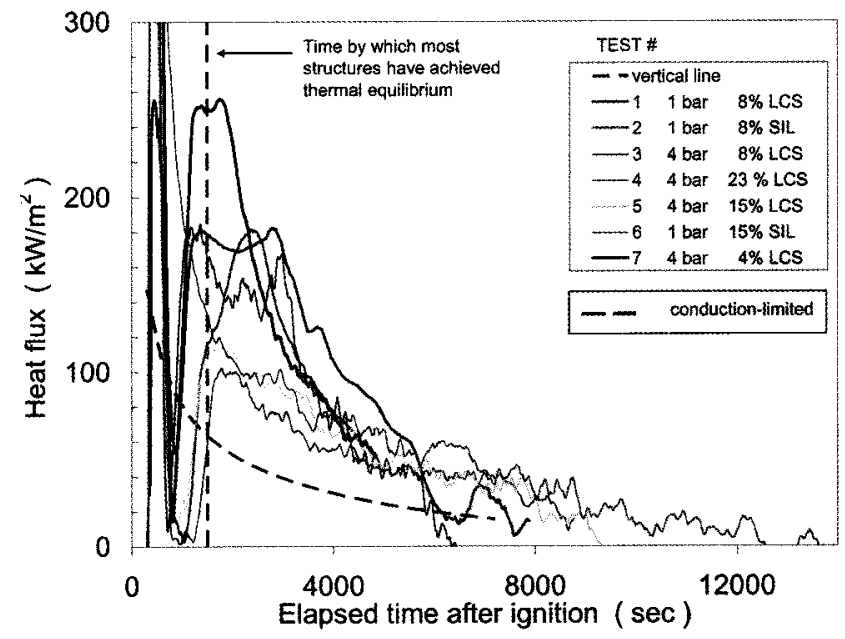

Fig. 24. SSWICS Heat Flux Data

available correlations that relate permeability to dryout heat flux for porous materials. Following the percolation tests, the specimens were sectioned radially to display the crack structure formed during the quench process (Fig. 23). The macroscopic strength of the sectioned crust specimens was then measured using a specially designed loading apparatus. [16] Finally, following the strength measurements, samples were collected from the crust fragments for chemical characterization.

The SSWICS heat flux data (Fig. 24) indicates that water is able to ingress into the crack structure that forms during quench, thereby augmenting the heat transfer rate. The effectiveness of this mechanism was found to decrease 
with increasing corium concrete content, but was not sensitive to concrete type. Surprisingly, the data did not show a significant effect of system pressure on the cooling rate, as would be expected on the basis of particle bed dryout models that are based on the premise of a countercurrent flow limitation.

The SSWICS crust strength data demonstrated that the actual mechanical strength of core material quenched by an overlying water pool is far weaker (by as much as two orders of magnitude) than that estimated for solid corium. This indicates that the crack structure formed during quench, not the composition, is the main determinant of crust strength. One uncertainty that must be factored into this conclusion is that the SSWICS tests were conducted without gas sparging. Thus, the crusts do not contain the additional porosity that develops within the crust during quench in the presence of sparging gas. However, in-situ crust strength measurements taken during the CCI tests (see discussion below) indicate that this increased porosity does not significantly affect the crust strength relative to that measured for the SSWICS tests.

Specifications for the CCI tests are provided in Table 5 . The overall facility layout was quite similar to that used in MACE (Fig. 2). However, the test section was redesigned to incorporate two concrete sidewalls as well as a concrete basemat (Fig. 25). This design could accommodate up to $35 \mathrm{~cm}$ of radial and/or axial ablation. As for the MACE tests, the other two sidewalls of the apparatus that backed up the tungsten electrodes were made from refractory $\mathrm{MgO}$ that was lined with crushed $\mathrm{UO}_{2}$ pellets. Following production of the corium melt through an exothermic chemical reaction, DEH was supplied to simulate decay heat. After a predefined period of core-concrete interaction, the cavity was flooded to obtain debris cooling data.

In terms of phenomenology, the $\mathrm{CCI}$ tests provided data on all four debris cooling mechanisms (Table 1). In addition, Test CCI- 2 provided data on water ingress at the interface between the core material and concrete sidewalls. This mechanism had been previously identified in the COTELS reactor material test series, $[7,8]$ but had not been observed in the MACE tests since these experiments were predominately $1-\mathrm{D}$.

As shown in Fig. 26, the heat flux during the five minute interval following cavity flooding was high for all tests. For the two tests conducted with siliceous concrete, the initial heat fluxes were close to the CHF limit. Thus, the heat fluxes were indicative of quenching of an upper surface crust that formed quickly after water addition for both of these tests. However, for CCI-2, the upper surface was essentially devoid of a crust when water was introduced. Thus, water was able to directly contact the

Table 5. CCI Test Specifications

\begin{tabular}{|c|c|c|c|}
\hline \multirow{2}{*}{ Parameter } & \multicolumn{3}{|c|}{ Specification for Test: } \\
\hline & CCI-1 & CCI-2 & CCI-3 \\
\hline Corium & $\mathrm{PWR}+8 \mathrm{wt} \% \mathrm{SIL}$ & PWR $+8 w t \%$ LCS & PWR $+15 \mathrm{wt} \% \mathrm{SIL}$ \\
\hline Concrete type ${ }^{\mathrm{a}}$ & SIL (US-type) & LCS & SIL (EU-type) \\
\hline Initial melt mass (depth) & $400 \mathrm{~kg}(25 \mathrm{~cm})$ & $400 \mathrm{~kg}(25 \mathrm{~cm})$ & $375 \mathrm{~kg}(25 \mathrm{~cm})$ \\
\hline Initial melt temperature & $1950^{\circ} \mathrm{C}$ & $1880^{\circ} \mathrm{C}$ & $1950^{\circ} \mathrm{C}$ \\
\hline Power input before water addition & Constant@150kW & Constant@120kW & Constant@120kW \\
\hline Criteria for water addition & \multicolumn{3}{|c|}{ 1) 5.5 hours of dry cavity operations, or 2) lateral/axial ablation reaches $30 \mathrm{~cm}$} \\
\hline Power input after water addition & \multicolumn{3}{|l|}{ Constant voltage } \\
\hline Test section sidewall construction & \multicolumn{3}{|c|}{ Nonelectrode walls: concrete; electrode walls: Inert } \\
\hline Basemat cross-section & \multicolumn{3}{|l|}{$50 \mathrm{~cm} \times 50 \mathrm{~cm}$} \\
\hline Lateral/Axial ablation limit & \multicolumn{3}{|l|}{$35 / 35 \mathrm{~cm}$} \\
\hline System pressure & \multicolumn{3}{|l|}{ Atmospheric } \\
\hline Melt formation tech. & \multicolumn{3}{|c|}{ Chemical reaction $(-30 \mathrm{~s})$} \\
\hline Melt heating technique & \multicolumn{3}{|l|}{$\mathrm{DEH}$} \\
\hline Inlet water flowrate/temp. & \multicolumn{3}{|l|}{$2 \mathrm{lps} / 20^{\circ} \mathrm{C}$} \\
\hline Water depth over melt & \multicolumn{3}{|l|}{$50 \pm 5 \mathrm{~cm}$} \\
\hline Test termination criteria & \multicolumn{3}{|c|}{ 1) $T_{\text {melt }}<$ concrete solidus, 2) ablation is arrested, or 3) ablation limit is reached. } \\
\hline
\end{tabular}




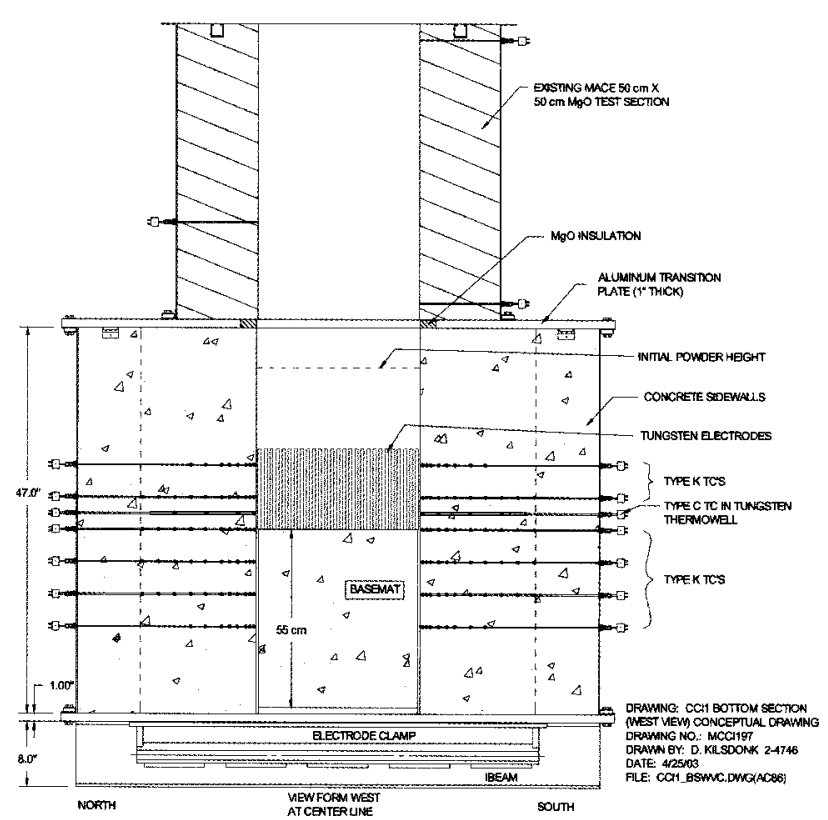

(a)

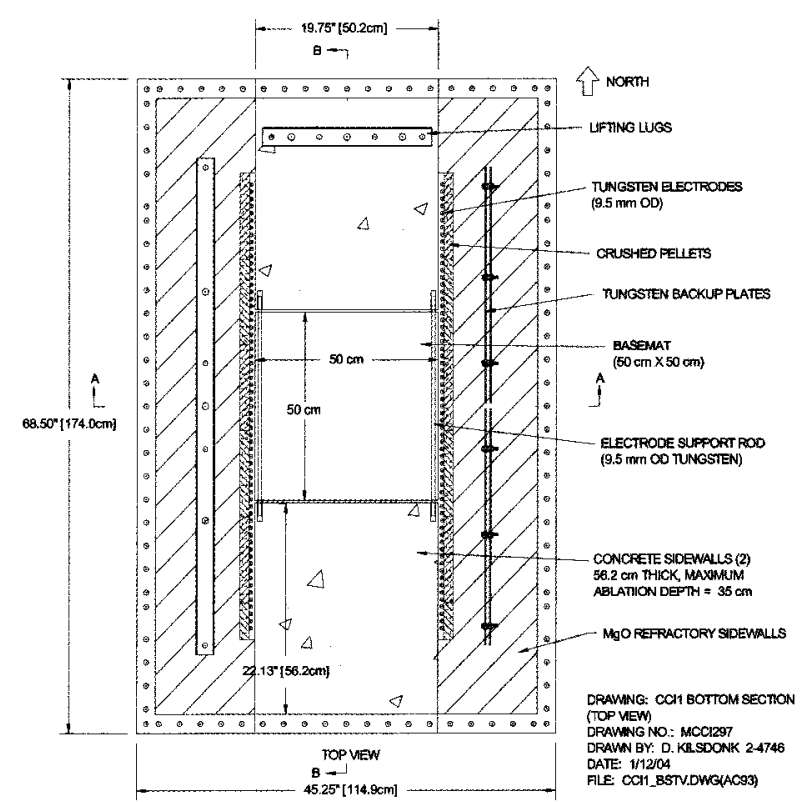

(b)

Fig. 25. (a) Side and (b) Top Views of the CCI Lower Test Section

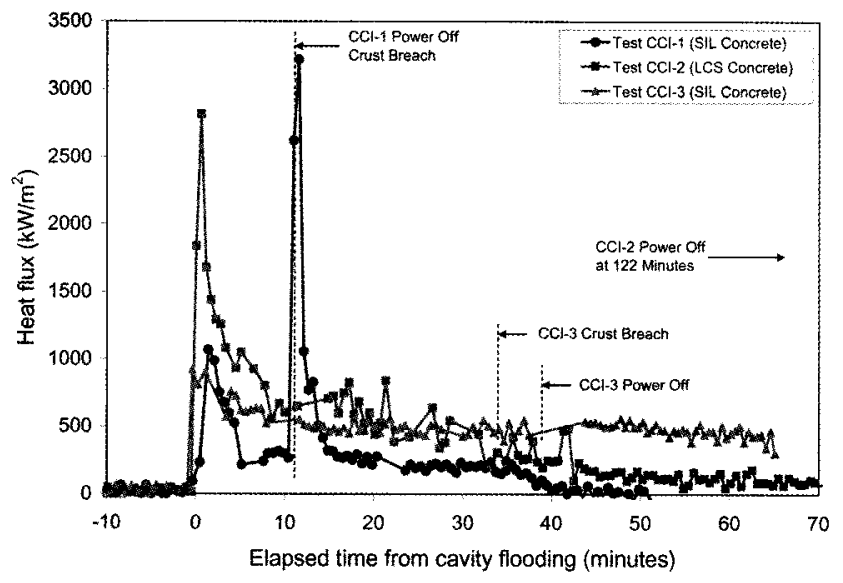

Fig. 26. CCI Test melt/water Heat Flux Data

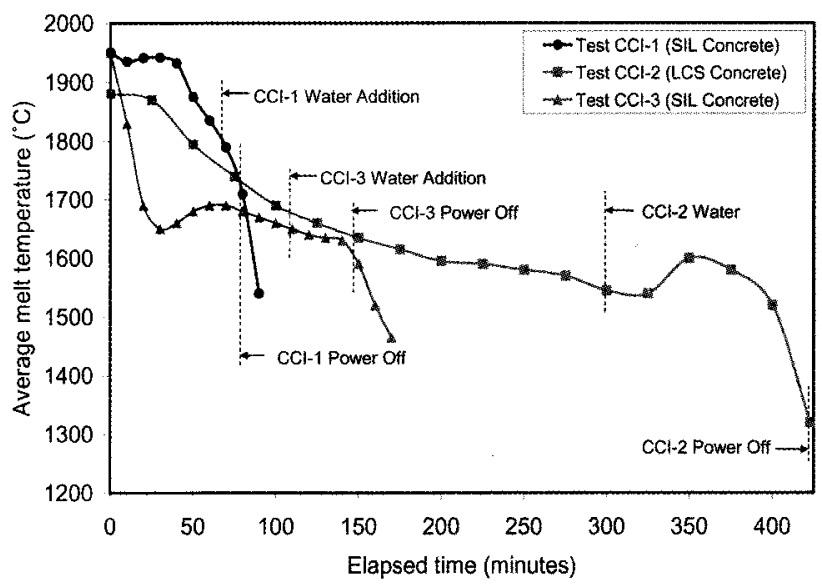

Fig. 27. CCI Test Average Melt Temperature Data melt, resulting in a bulk cooling transient in which the initial cooling rate approached $3 \mathrm{MW} / \mathrm{m}^{2}$. This heat flux is consistent with that observed for the previous MACE tests with the same concrete type (LCS). However, the heat flux eventually fell below the $\mathrm{CHF}$ limit at $\sim 5$ minutes. At this time, a stable crust formed, thereby terminating the bulk cooling transient.

The tests did not generally exhibit a decrease in overall melt temperature after cavity flooding. This is despite the fact that the heat flux and power supply responses both indicated substantial debris cooling. As for the MACE tests, this type of behavior has been explained by a latent heat transfer process in which a quench front develops, as opposed to a sensible heat transfer process in which the entire melt mass is cooled by convection. The posttest debris morphologies were also consistent with development of quenched debris zones.

Following the initial heat transfer phase, the heat fluxes for both siliceous concrete tests were lower compared to 
the LCS concrete test. With the exception of the crust breach event in CCI-1 (discussed below), the data indicates that the heat flux increased with concrete gas content. After the initial transients (i.e., $t>5$ minutes), the heat fluxes were several times higher than that observed in the SSWICS water ingression tests. One significant difference between the two test series was the presence of gas sparging in the CCI tests. Thus, one possible explanation for the enhanced cooling is that the extent of interconnected porosity that forms in the corium during quench increases when gas sparging is present. The posttest debris configurations are consistent with this observation (Fig. 28). The increased porosity apparently provides additional flow area for water to penetrate into the material relative to that formed due to thermally-induced crack formation and propagation.

As noted earlier, aside from the water ingression mechanism, the CCI tests also provided integral data on the melt eruption cooling. In particular, significant eruptions were observed for CCI-2. However, no spontaneous eruptions were observed after cavity flooding for the two tests conducted with siliceous concrete.

In terms of the crust breach mechanism, both siliceous concrete tests provided data on in-situ crust strength, while Test CCI-1 also provided data on the extent of cooling after crust breach. The data indicates that the crust material formed during quench is very weak. This finding is consistent with the SSWICS crust strength measurements. However, the CCI measurements were significant because they were carried out under prototypic temperature boundary conditions before the material had cooled to room temperature. Aside from the strength data, the crust breach event in $\mathrm{CCI}-1$ caused a significant transient increase in the debris cooling rate (see Fig. 26 at $\mathrm{t}=10$ minutes). In particular, a large melt eruption occurred, resulting in a heat flux peak that significantly exceeded the CHF limitation. After the breach, the heat flux steadily declined over the next five minutes to a plateau which was similar to that observed prior to breach. In general, the data indicates that breach events could lead to significant transient increases in the debris cooling rate at plant scale.

\section{DISCUSSION}

As indicated by the above review, ex-vessel debris coolability has been the subject of extensive research over the last 20 years. The first objective of this section is to assess the adequacy of the existing database insofar as directly demonstrating coolability. This discussion will show that although quite good cooling behavior has been observed under certain conditions, scaling effects have significantly influenced the outcomes of many of the experiments, making it uncertain whether or not core melt can be definitively quenched under a wide range of conditions. On this basis, the research trend over the last several years has been to develop phenomenological models of the various cooling mechanisms in order to quantify the extent that these mechanisms can contribute to long-term coolability. The second objective of this section is to summarize the status of these modeling activities. These various models have been deployed to different extents in system-level codes that analyze coreconcrete interaction. These codes are able to link the interrelated phenomenological effects, thereby allowing the results to be extrapolated to plant conditions. Thus, the third and final objective of this section is to exercise one of these codes to scope out an approximate debris coolability envelope for the two concrete types that are commonly used in power plant construction around the world.

\subsection{Database Assessment}

The coolability database consists of tests conducted with low temperature glycerin/liquid nitrogen simulants, [4] high temperature stainless steel [5] and oxide [6] simulants, and finally experiments conducted with reactor materials at intermediate $[7,8]$ and large [9-16] scale. To date, only a few tests have exhibited the type of aggressive, sustained cooling behavior that would be needed to demonstrate coolability during core-concrete interaction; these tests include: i) the glycerin/liquid nitrogen experiments of Theofanous et. al., [4] ii) the intermediate scale reactor material tests conducted as part of the COTELS project, $[7,8]$ and iii) the large scale MACE and OECD/MCCI reactor material tests conducted with LCS concrete. [9-13] One common factor for tests that cooled well vs. those that did not was that crust contact with the underlying melt was maintained as the quench process progressed. As discussed extensively over the course of this review, sustained contact between the crust and underlying melt is the expected condition at plant scale. The heat transfer mechanism credited with providing a coolable debris configuration in the experiments by Theofanous et al. is volcanic eruptions, leading to a high surface area melt configuration. This cooling mechanism was originally observed in the MACE Scoping Test, but progression to complete quench was not achieved in that test due to the fact that an anchored crust formed, eventually leading to separation of the melt from the crust. Melt eruptions have been observed in all reactor material experiments conducted with LCS concrete. Unfortunately though, no spontaneous eruptions have been observed in tests conducted with siliceous concrete as part of the MACE and OECD/MCCI programs carried out at Argonne.

In the COTELS experiments, coolable debris configurations were achieved through the combined mechanisms of particle bed formation (presumably by eruptions, but details not provided [8]), and water ingression through cracks and fissures into the coherent crust layer. These tests were conducted with 2-D basalt 


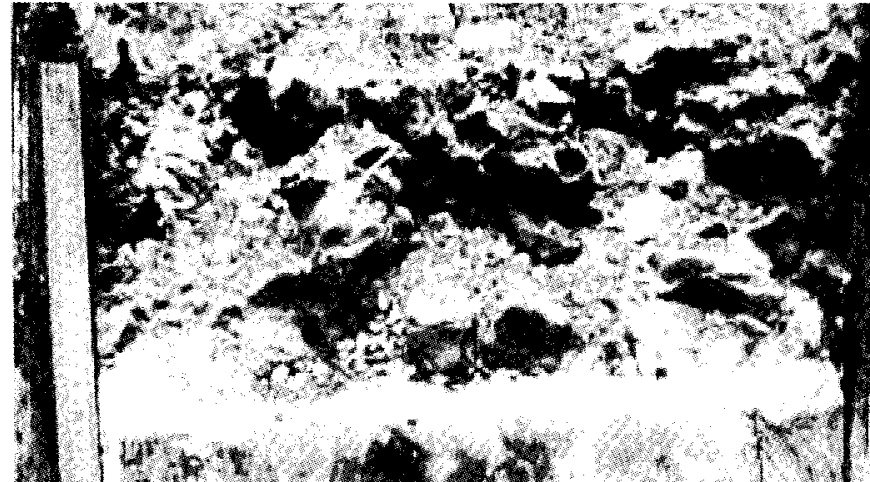

(a)

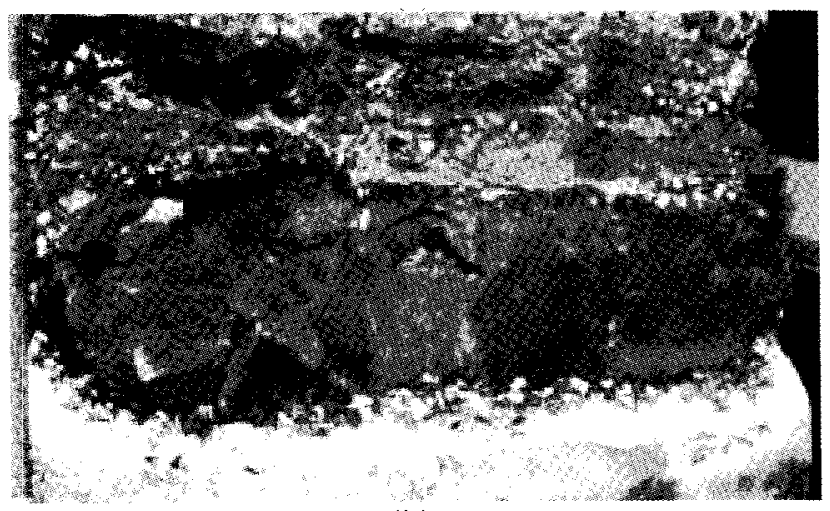

(b)

Fig. 28. Debris Morphology for a) CCI-2 and b) CCI-3

concrete crucibles; basalt is similar to siliceous. Crust anchoring and melt separation did not occur in these tests, which is felt to be a key reason why these tests cooled so well. Moreover, the fact that particle beds formed is reassuring from the viewpoint of demonstrating that melt eruptions can contribute to coolability for high silica content concretes, given the Argonne test results. However, in the evaluation of the COTELS tests, the following experiment conditions should be noted which may have favorably influenced the cooling behavior: i) specific power density was $\sim 10$ times higher than prototypic, and ii) the initial melt superheats were nominally $730^{\circ} \mathrm{C}$ with respect to the oxide liquidus of $2200^{\circ} \mathrm{C}$.

The COTELS tests also demonstrated that water is able to ingress through cracks and fissures in the bulk core material, as well as the core-concrete interface around the periphery of the solidified debris. However, the relative contributions of these two mechanisms was not quantified, and so extrapolation to plant conditions is difficult since the edge cooling effect would be greatly reduced at plant scale.

The MACE tests also demonstrated that water ingression can contribute to coolability. For example, in test $\mathrm{M} 3 \mathrm{~b}$ the data indicates that a massive, $\sim 10 \mathrm{~cm}$ thick crust formed over the first 20 minutes of the experiment, amounting to $\sim 1 / 2$ the initial melt mass. The upwards heat transfer rate confirms that the heat removal could not have occurred if heat transfer through the crust was limited by conduction alone. Posttest measurements indicate that this thick bridge crust was permeable to both gas and water flows. The test data also indicates that after 20 minutes of melt/water interaction, the crust anchored to the test section sidewalls leading to melt/crust separation. After separation, the melt/water heat transfer rate dropped significantly, thereby terminating the initial quenching event. This data further illustrates the importance of maintaining melt/crust contact. If contact had been maintained during $\mathrm{M} 3 \mathrm{~b}$, the initial quenching transient may have proceeded further; possibly to completion.

Due to these observations, the SSWICS separate effect test series was carried out to quantify the extent of wateringression cooling as a function of melt composition and system pressure. $[14,15]$ The results demonstrated that the extent of water ingression increases with decreasing concrete content in the melt, and is (somewhat surprisingly) not significantly influenced by system pressure. The crust dryout limits determined in these tests are not as high as one would expect based on the crusts formed during the integral effect tests in which gas sparging is present. One shortcoming of the original SSWICS test series is that the experiments were conducted with inert basemats and so gas sparging was absent during quench. This is being addressed in the current MCCI-2 program in which a controlled gas flowrate is provided through the basemat to determine if sparging helps or hinders the water ingression rate. Early results indicate that gas sparging increases the crust permeability, and thereby, the water ingression cooling rate. However, results from the current program are proprietary and thus additional discussion cannot be provided.

Aside from the MACE tests, additional integral effect cooling data was obtained in the CCI test series. [11-13] These test results are particularly valuable because the crusts did not anchor to form large intervening gaps as occurred in the MACE test series. The single test conducted with LCS concrete (CCI-2) cooled exceptionally well, with complete quench achieved over a timescale of approximately an hour. Both water ingression and melt eruption cooling behaviors were observed. The posttest debris porosity in this experiment was very high (see Fig. 28(a)), which was a key contributor to the coolability that was observed. This experiment is deemed to be the best 
demonstration of debris coolability achieved to date.

The two CCI tests conducted with siliceous concrete (CCI-1 and -3) also cooled well compared to that seen in the MACE tests where anchoring occurred, but the cooling rate was not as good as that for the LCS concrete type (CCI-2). Water ingression was also observed in these tests, but not to the extent that was achieved in CCI-2. In general, melts containing a high degree of silica seem to be less susceptible to thermally-induced cracking due to the very low coefficient of thermal expansion for quartz. The reduced extent of ingression can be understood by comparing the posttest debris morphologies between the two test types (see Fig. 28). As previously noted, melt eruptions were not observed in either test with siliceous concrete.

Based on this review and keeping in mind the scaling (i.e., wall) effects that have been observed in many of the tests, it is not clear that debris coolability can be achieved under the full extent of conditions that may be encountered in a plant accident. However, the database nonetheless suggests that extensive abatement or even quench of the core material may be obtained through several cooling mechanisms under the expected plant condition of sustained melt/crust contact. The research trend in the last few years has thus been to model these cooling mechanisms to form the technical basis for extrapolating results to plant conditions. The status of these modeling efforts is described next.

\subsection{Modeling Status}

The discussion is framed in terms of the four coolng mechanisms that have been identified; namely i) bulk cooling, ii) water ingression, iii) melt eruptions, and iv) crust breach.

\subsubsection{Bulk Cooling}

Models for prediction of the melt/water heat transfer rate during bulk cooling have been developed, [22] as well as models for prediction of the critical superficial gas velocity at which stable crust formation occurs, thereby terminating the bulk cooling phase. [3] These models have been compared with MACE test data with favorable results. $[23,24]$ Thus, of the four cooling mechanisms that have been identified, bulk cooling is perceived to be the best understood since models exist, and limited validation of the models against test data has been performed. The test data as well as the models are deemed to be directly applicable to the reactor case, since the interaction is scale independent as long as the test section lateral dimension is several times the sparging gas bubble diameter. This condition was satisfied for all reactor material tests.

Aside from coolant properties, the models are dependent upon the sparging rate, gas bubble diameter, melt/crust thermophysical properties as well as the crust fracture strength. Crust strength data has been obtained as part of the MACE and MCCI programs, [16] and this database is fairly substantial. The heat transfer coefficient during bulk cooling is linearly proportional to the gas sparging rate. Therefore, the model is sensitive to system pressure since the melt sparging rate is inversely proportional to system pressure.

\subsubsection{Water Ingression}

Fundamental modeling of water ingression processes has been underway for some time in the area of geological research. In particular, Lister [25] developed a theory for the mechanism of penetration of water into hot rock by using the concept of a cracking front which separates a convective region in cracked porous rock from the conductive boundary layer below it. The material in the conduction boundary layer cools, and as a result, builds up horizontal tensile stress as the resistance to creep rises. Cracks within the material then propagate when the tensile stress exceeds the overburden pressure, resulting in stable downward propagation of a pattern of subvertical (polygonal) cracks. Further cooling and shrinkage widens the cracks to the percolation of water, so that the effective bulk permeability is a strong function of crack spacing and temperature. Equations were developed for the bulk permeability based on the above modeling approach, which permits the evaluation of the dryout heat flux. This theory has been used to explain qualitative aspects of cooling of the earth's mantle, in particular geological ridge crest heat-flow and seismic data. The attractive aspect of this modeling is that it provides a method for calculating the permeability based on the thermophysical properties (and temperatures) of the material involved, which includes the crust density, specific heat, thermal conductivity, linear expansion coefficient, fracture stress, Poisson's ratio, and the elastic modulus, in addition to properties of the coolant.

In a recent study, Epstein [26] developed a purely thermal, steady state model of the water ingression process. Epstein then combined the thermal model with Lister's description of the cracking front to obtain an approximate solution for the dryout heat flux, as well as the rate of downward solidification of the crust. Epstein found that the combined model is capable of predicting the field measurements obtained by watering of molten lava flow. [27] Application of Epstein's model to the case of MCCI indicates that corium solidification by water ingression is not possible if the permeability of corium is the same as water-cooled lava (rock). However, whether the creep and cracking behavior of corium is similar to rock can only be answered though wellcontrolled experiments on the solidification rate of corium under a layer of water. [26] This was one of several technical justifications for the conduct of the SSWICS tests described earlier. [14-16] As part of the analysis efforts supporting the SSWICS test series, Lomperski and Farmer [14-16] extended the Epstein 
model to remove some of the empirical assumptions and make the correlation applicable to a wider range of conditions that might be expected in a plant accident. In particular, a simple analytical solution was proposed for evaluating the material temperature at onset of cracking. In addition, methods were proposed for evaluating key material mechanical properties (i.e., Young's modulus, tensile strength, and thermal expansion coefficient) as a function of melt composition. These considerations led to a correlation for the corium dryout heat flux with one empirical constant remaining, and this constant was adjusted to fit the SSWICS dryout heat flux data. [16] As noted earlier, this correlation is conservative in terms of predicting dryout limits for crusts formed in the presence of gas sparging. Efforts are underway as part of the MCCI-2 program to model this effect, but results have not been reported in the open literature at this point.

\subsubsection{Melt Eruptions}

Motivated by the melt eruptions observed in the MACE Scoping Test, Bonnet and Seiler [20] developed a parametric model of particle bed formation by means of melt entrainment during MCCI. In this model, melt dispersal is calculated by assuming that the melt entrainment rate is proportional to the gas volumetric flow rate times an entrainment coefficient. The entrained melt is assumed to accumulate on the upper surface of the crust in the form of a particle bed of specified porosity and particle diameter. The entrainment coefficient is an input parameter. Parametric calculations were performed with the model to determine if debris bed formation by the mechanism of melt entrainment is a viable means of achieving long term coolability. The results of the analysis indicated that transformation into a quenched debris bed could be achieved for entrainment coefficients as low as 0.1 to $0.01 \%$ at atmospheric pressure. The entrainment process was found to be more efficient with concretes of higher gas content (since entrainment is proportional to gas release). The entrainment efficiency decreased with increasing system pressure (since gas volumetric flowrate from MCCI is inversely proportional to system pressure). The entrainment coefficient was also found to be a sensitive input parameter. The initial melt temperature was, however, found to have little effect on the entrainment process.

Aside from the reactor material experiments, the PERCOLA experiment program was carried out at the Commissariat â l'Energie Atomique (CEA) in Grenoble by Tourniaire et al. [28] to provide fundamental insights into the eruption process under well-controlled experiment conditions. These tests utilized simulant materials with different viscosities to simulate the enrichment of corium with silica $\left(\mathrm{SiO}_{2}\right)$ during core-concrete interaction. Based on these data, Tourniaire and Seiler [29] developed models of liquid ejection for the single-phase extrusion (or 'fountain') and two phase jetting eruption mechanisms through a floating solid layer that represents the interfacial crust that forms during core-concrete interaction. They compared their solutions with the test results and found that the principal trends in the test data were reasonably reproduced by the models. The results of their work highlighted the importance of modeling the frictional pressure drop through the solid layer, and the influence of the pressure drop on the calculation of liquid ejection for viscous fluids.

Although the models of Tourniaire and Seiler [29] provide a sound technical basis for evaluating the entrainment rate when freezing effects are absent, these models need to be extended to include the effects of melt solidification and gas flow through the permeable crust that develops at the interface between the melt pool and overlying coolant. Other needs are the ability to predict the diameter of the vent holes through the crust, and also the eruption hole site density within the crust. [29] On this basis, Farmer [30] extended these existing models to include melt solidification and gas flow effects through the crust that develops at the interface between the melt pool and overlying coolant during core-concrete interaction. These efforts led to analytical solutions for the active melt eruption hole site density, as well as the average eruption hole diameter. The modeling considered the thermal hydraulic flow, pressure drop, and freezing processes involved with melt ejections through a crust that is permeable to both gas and water flows. Although significant progress was made with this modeling effort, two-phase flow effects still need to be factored into that analysis to ensure a robust treatment.

\subsubsection{Crust Breach}

One additional mechanism that has been postulated as a contributor to debris coolability under prototypic conditions is breach of a suspended bridge crust, leading to flooding of water into the intervening void between the melt and overlying debris. Sustained anchoring and separation of a crust from the melt is not expected in a plant accident due to the large lateral span of the drywell/ pedestal regions of these structures (typically 6 meters). However, the MACE test results showed that intermittent or localized crust anchoring to the pedestal walls is plausible. The thick crusts that form from water ingression may have sufficient mechanical strength to bond to the pedestal walls and temporarily separate from the ongoing MCCI. The voided region which results could take the form of an annular ring, due to potential slumping of the suspended crust in the central region. This configuration is, however, not expected to be stable due to mechanical weakness of the crust [16] coupled with the combined loads on the crust that consist of the crust weight plus the weights of the overlying water and particle bed. Eventually the suspended crust will fail, leading to rapid ingression of water beneath the crust.

During a crust breach event, water will most likely 
flow down through the newly formed opening(s) and fill the intervening voided region. Depending upon the MCCI conditions at the time of breach, a renewed bulk cooling phase may occur. The introduction of water into the void will provide additional cooling of any crust material which remains attached to the pedestal sidewalls from the initial breach event. A crust will eventually form over the underlying MCCI zone. After incipient crust formation, the potential exists for water ingression and melt dispersal cooling mechanisms to be reactivated. If this process continues, the final debris configuration could consist of layers of particles/porous lava interspersed with layers of permeable crust in a configuration reminiscent of a honeycomb.

Modeling of crust bridging is fairly straightforward; i.e., the analysis consists of utilizing correlations for stress in a flat plat as a function of plate area, thickness, and the loading which consists of the weight of the crust itself, as well as the weights of the overlying water and particle beds. [24] Crust mechanical strength data from the tests [16] is the final model input required to determine the plate (viz. crust) thickness required to be mechanically stable in the reactor cavity. This analysis indicates that crust thicknesses in the range of 20 to $30 \mathrm{~cm}$ would need to form before anchoring with separation would occur in a typical $6 \mathrm{~m}$ cavity span. This thickness is of the same order as the melt depth calculated in some accident sequences. Thus, if the crust were to anchor at this point, the core-concrete interaction would be effectively terminated since the heat removal would be sufficient to freeze and stabilize a large melt depth. The primary benefit of the modeling in this area is that for most plant simulations, one can assume a floating crust boundary condition, which greatly simplifies the modeling approach.

\subsection{Model Extrapolation to Plant Conditions}

Coolability models have been deployed to various extents in various integral codes that are able to link the interrelated phenomenological effects, thereby allowing the results to be extrapolated to plant conditions. One such code (CORQUENCH [24]) has been upgraded to include the bulk cooling, [3,22] water ingression, [15] melt eruption, [24,30] and crust breach [24] modeling results. This model has been exercised [31] to scope out an approximate debris coolability envelope for two common types of concrete used in many operating plants around the world. The calculations were run using a floating crust boundary condition for plant conditions, which is the expected boundary condition based on the test data and supporting analyses. [16] The calculations were carried out parameterizing on the initial melt depth, as well as the concrete content in the melt at the time of cavity flooding. The later parametric variation is based on the consideration that water may be added at different times in the accident sequence, which causes the concrete content to be different due to ongoing core-concrete interaction. All runs were made assuming a 4 bar containment pressure that is held constant over the course of the calculation.

The results for LCS concrete (Fig. 29) indicate that melt stabilization may be achieved in under one meter of axial ablation as long as the cavity is flooded before the melt concrete content exceeds 15 wt \% for initial melt depths ranging up to $40 \mathrm{~cm}$. Under these conditions, stabilization may take up to 10 hours to achieve. However, if flooding is delayed past this point, then the possibility of stabilizing the melt becomes much less likely.

For the same set of modeling assumptions, the results for siliceous concrete (Fig. 30) indicate a much narrower coolability range. In particular, melt stabilization may not be achieved in under one meter of axial ablation unless the initial melt depth is fairly shallow (i.e., $\leq 20 \mathrm{~cm}$ ), and

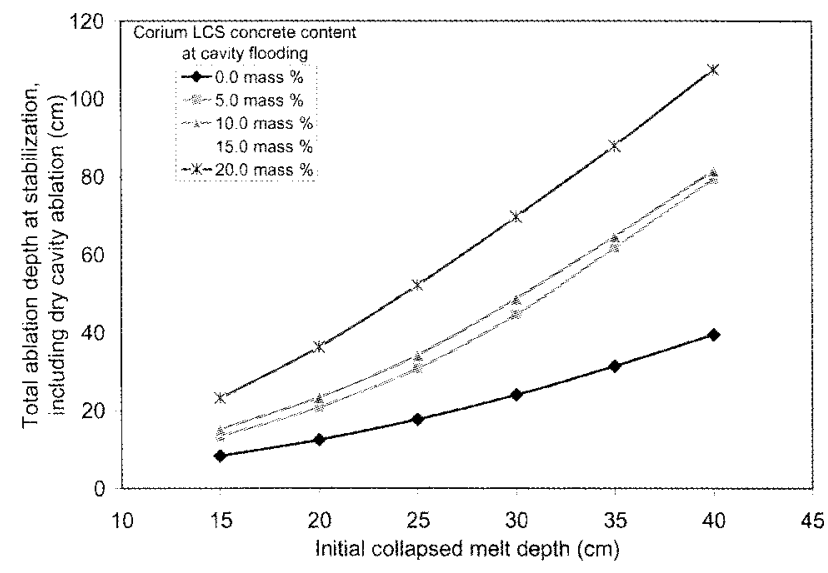

Fig. 29. Prediction of Basemat Ablation Depth at Melt Stabilization: LCS Concrete

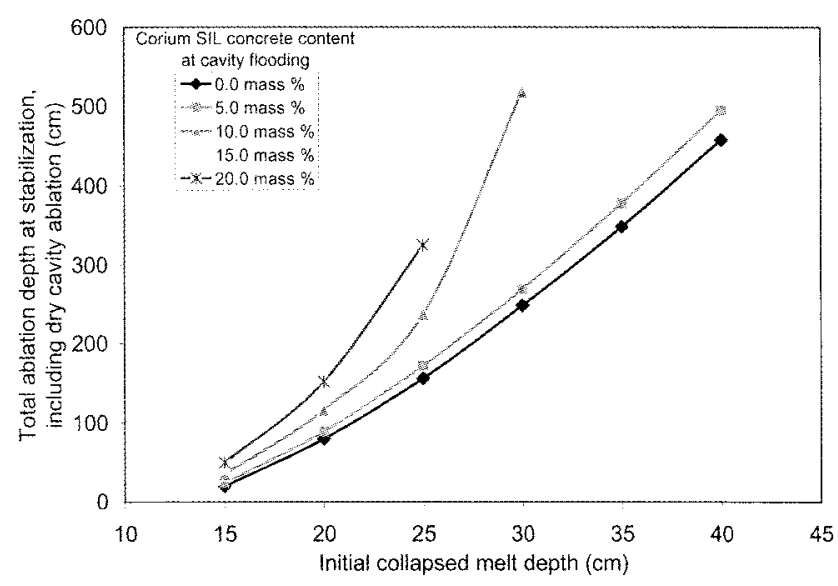

Fig. 30. Prediction of Basemat Ablation Depth at Melt Stabilization: SIL Concrete 
the cavity is flooded before the melt concrete content exceeds $10 \mathrm{wt} \%$. In this range, coolability may take up to two days to achieve assuming that melt eruptions are active during the quenching process. However, as discussed earlier, spontaneous eruptions were not observed with water present in several of the experiments conducted to date with this concrete type. Conversely, if the containment design is such that melt depths up to $40 \mathrm{~cm}$ may be encountered, then stabilization may not be achieved unless the design can accommodate up to five meters of axial ablation, and only if the cavity is flooded early (i.e., concrete content $\leq 5 \mathrm{wt} \%$ ). Under these conditions, stabilization will take in excess of one week to achieve. Note again that this result is based on the assumption that melt eruptions are active for the case of siliceous concrete.

Although the calculations shown here are based on the experiment findings from the various test programs, these tests were all small relative to plant conditions. At plant scale, the cooling efficiency could be influenced or improved by other phenomena which could be masked at the scale of these tests. For example, breached crusts could lead to underwater volcanic-type pours which may also result in debris fragmentation.

\section{ACCIDENT MANAGEMENT FOR ADVANCED PLANTS}

The primary objective of $R \& D$ efforts in the area of ex-vessel corium coolability has been to demonstrate through a combination of experiments and analysis that core melt interacting with concrete can be quenched and rendered coolable over a wide range of conditions. Unfortunately, this has been an extremely difficult objective to achieve. Results to date indicate that modestly deep (i.e., $<40 \mathrm{~cm}$ ) core melt pools interacting with LCS concrete should be coolable. However, for deeper melts, or for melts interacting with siliceous concrete, the same conclusion cannot be drawn.

For new Generation 3+ plants, the focus has been on achieving long term coolability and melt stabilization as a key design objective. Vendors took note of the results coming out of the debris coolability R\&D programs and decided that engineering features to enhance coolability would need to be built into new plant designs. As described by Sehgal, [1] two approaches have been taken: i) invessel melt stabilization and retention, and ii) ex-vessel coolability and melt retention. In-vessel melt retention relies on flooding of the reactor pit and submerging the vessel lower head with water. The design challenge is then to ensure that the thermal load to the water pool through the head does not exceed the CHF limit with sufficient margin. This approach has been adopted for the AP600 [32] and AP1000 [33] plant designs.

In terms of ex-vessel conditions, two methods have been explored for achieving melt stabilization:
1) A crucible-type technique in which sacrificial material is first introduced into the melt through ablation at the melt/crucible boundary (with the additives acting to lower the melt pool freezing point), and then cooling of the crucible exterior boundary with water.

2) Melt fragmentation, in which water is introduced at the bottom of the melt pool at a slight overpressure, and the ensuing steam formation acts to cool and solidify the melt in a highly porous configuration that is readily permeable by water.

The crucible technique has been adopted for the $\mathrm{EPR}^{\mathrm{TM}}[34]$ that features a spreading room adjacent to the reactor pit in which the melt is cooled by water from the bottom and top after spreading is completed. The VVER1000 also utilizes a crucible technique, but in this design the crucible is located directly below the reactor vessel. Full details of the approach for the VVER-1000 are provided in a companion paper for this special edition of Nuclear Engineering and Technology. [35]

The melt fragmentation technique, denoted COMET, was pioneered by Forschungszentrum Karlsruhe (FZK). Both simulant and reactor material tests have shown that this is a very effective means for quenching and stabilizing core melt. [36,37] However, to the best of the authors knowledge, this concept has not been deployed in any current reactor design. Another concept that has been developed by Sehgal and coworkers $[38,39]$ are downcomers that provide a pathway to channel water from the top of the melt pool to the bottom, where the water is introduced into the debris thereby achieving the same beneficial results as those observed for COMET. This technique is thought to be useful as a simple backfit to existing plants to improve the chances of cooling and stabilizing the core melt in the event of a severe accident.

Additional details regarding these new design features, as well as the research efforts that underpin them, are provided by Sehgal. [1]

\section{SUMMARY AND CONCLUSIONS}

Ex-vessel debris coolability research has focused on determining the effectiveness of water in terminating a core-concrete interaction by flooding the interacting masses from above, thereby quenching the molten core debris and rendering it permanently coolable. Successful quenching of the core melt would prevent basemat melt through, as well as continued containment pressurization by non-condensable gas production, and so the accident progression would be successfully terminated without release of radioactivity to the environment. Based on these potential merits, coolability has been the focus of extensive research over the last 20 years as a potential accident management strategy for current plants. As a part of this work, both simulant and reactor material experiments have been carried out to provide a database 
to support model development and code validation activities. These tests have revealed four mechanisms that can contribute to core debris quenching: i) bulk cooling in which gas sparging is sufficient to preclude stable crust formation at the melt/water interface, and therefore efficient heat transfer is achieved; ii) water ingression through fissures in the core material that augments what otherwise would be a conduction-limited cooling process; iii) melt (or volcanic) eruptions that lead to a highly porous overlying particle bed that is readily coolable, and iv) transient breach of crusts that form during the quench process, leading to water infiltration below the crust with concurrent increase in the debris cooling rate.

Although the identified cooling mechanisms certainly increase the debris cooling rate, scaling effects in many of the tests have significantly influenced test outcomes, even at extremely large experiment scale at up to 2 metric tons core melt mass. These occurrences have made it difficult to declare with certainty that a core melt can always be quenched under a wide range of conditions. On this basis, the research trend over the last several years has been to develop phenomenological models of the various cooling mechanisms observed in the tests in order to quantify the extent that these mechanisms can contribute to coolability. These various phenomenological models can be deployed in codes that are able to link the interrelated phenomenological effects, thereby allowing the results to be extrapolated to plant conditions. One such model was upgraded to include these findings, and the model was used to scope out an approximate debris coolability envelope for two concrete types. The results for limestone/ common sand concrete indicate that melt stabilization may be achievable in under one meter of axial ablation as long as the cavity is flooded before the melt concrete content exceeds $15 \mathrm{wt} \%$ and the initial melt depth is $\leq 40 \mathrm{~cm}$. Conversely, for siliceous concrete, stabilization may not be achieved in under one meter of ablation unless the initial melt depth is fairly shallow (i.e., $\leq 20 \mathrm{~cm}$ ), and the cavity is flooded before the melt concrete content exceeds 10 wt $\%$.

In light of these findings, vendors have opted to build in engineering features to enhance debris coolability into the new Gen 3+LWR designs. These approaches include in-vessel retention adopted for the APR 1000, and crucibletype designs that have been deployed in the EPR and VVER1000 designs.

\section{ACKNOWLEDGMENTS}

The Argonne work described in this review has been carried out as part of two major experiment programs. The initial MACE program was managed by the Electric Power Research Institute (EPRI) and was supported by the U.S. NRC, DOE, EPRI, and an international consortium. The follow-on OECD/MCCI program is managed by the NRC and is sponsored by a consortium of countries within the Organization for Economic
Cooperation and Development (OECD). This support is gratefully acknowledged.

\section{REFERENCES}

[1 ] B. R. Sehgal, "Light Water Reactor (LWR) Safety," Nucl. Eng. Technol., 38, 1 (2006).

[2] B.R. Sehgal, "Accomplishments and Challenges of the Severe Accident Research," Nucl. Eng. Design, 210, 79 (2001).

[3] M. T. Farmer et al., "Modeling and Database for MeltWater Interfacial Heat Transfer," $2^{\text {nd }}$ CSNI Specialist Meeting on Core Debris-Concrete Interactions, Karlsruhe, Germany, April 1-3, 1992.

[4] T. G. Theofanous, C. Liu, and W. W. Yuen, "Coolability and Quench of Corium-Concrete Interactions by TopFlooding," MACE-TR-D14, Electric Power Research Institute (1998).

[5] R. E. Blose, J. E. Gronager, A. J. Suo-Anttila, and J. E. Brockman, "SWISS: Sustained Heated Metallic Melt/ Concrete Interactions With Overlying Water Pools," NUREG/CR-4727 (1987).

[6] R. E. Blose, D. A. Powers, E. R. Copus, J. E. Brockmann, R. B. Simpson, and D. A. Lucero, "Core-Concrete Interactions with Overlying Water Pools - The WETCOR1 Test," NUREG/CR-5907 (1993).

[ 7 ] H. Nagasaka, M. Kato, I. Sakaki, Y. Cherepnin, Y. Vasilyev, A. Kolodeshnikov, V. Zhdanov, and V. Zuev, "COTELS Project (1): Overview of Project to Study FCI and MCCI During a Severe Accident," OECD Workshop on Ex-Vessel Debris Coolability, Karlsruhe, Germany, November 15$18,1999$.

[8] H. Nagasaka, I. Sakaki, M. Kato, Y. Vasilyev, A. Kolodeshnikov, and V. Zhdanov, "COTELS Project (3): Ex-vessel Debris Cooling Tests," OECD Workshop on ExVessel Debris Coolability, Karlsruhe, Germany, November 15-18, 1999.

[9] M. T. Farmer, B. W. Spencer, D. J. Kilsdonk, and R. W. Aeschlimann, "Results of MACE Corium Coolability Experiments M0 and M1b," Proceedings $8^{\text {th }}$ Int. Conf. on Nucl. Eng., Baltimore, MD USA, April 2-6, 2000.

[10] M. T. Farmer, B. W. Spencer, J. L. Binder, and D. J. Hill, "Status and Future Direction of the Melt Attack and Coolability Experiments (MACE) Program at Argonne National Laboratory," Proceedings $9^{\text {th }}$ Int. Conf. on Nucl. Eng., Nice, France, April 8-12, 2001.

[11] M. T. Farmer, S. Lomperski, and S. Basu, "Results of Reactor Material Experiments Investigating 2-D CoreConcrete Interaction and Debris Coolability," Proceedings ICAPP '04, Pittsburgh, PA USA, June 13-17, 2004.

[12] M. T. Farmer, S. Lomperski, and S. Basu, "The Results of the $\mathrm{CCI}-2$ Reactor Material Experiment Investigating 2-D Core-Concrete Interaction and Debris Coolability," $11^{\text {th }}$ International Topical Meeting on Nuclear Reactor ThermalHydraulics (NURETH-11), Avignon, France, October 2-6, 2005.

[13] M. T. Farmer, S. Lomperski, D. Kilsdonk, R. W. Aeschlimann, and S. Basu, "A Summary of Findings from the Melt Coolability and Concrete Interaction (MCCI) Program," Proceedings ICAPP '07, Nice, France, May 13-18, 2007.

[14] S. Lomperski and M. T. Farmer, "Experimental Evaluation of the Water Ingression Mechanism for Corium Cooling," 
Nuclear Eng. Design, 237, 905 (2006).

[15] S. Lomperski, M. T. Farmer, and S. Basu, "Experimental Investigation of Corium Quenching at Elevated Pressure," Nuclear Eng. Design, 2362271 (2006).

[16] S. Lomperski and M. T. Farmer, "Corium Crust Strength Measurements," accepted for publication in Nuclear Eng. Design (2009).

[17] M. T. Farmer, B. W. Spencer, and R. W. Aeschlimann, "Liquidus/Solidus and $\mathrm{Zr}$ Solubility Measurements for PWR and BWR Core Melt Compositions," OECD Workshop on Ex-Vessel Debris Coolability, Karlsruhe, Germany, November 15-18, 1999.

[18] J. J. Sienicki and B. W. Spencer, "The Jet Impingement Stage of Molten Core-Concrete Interactions," OECD CSNI Specialist Meeting on Core Debris/Concrete Interactions, Electric Power Research Institute, Palo Alto, CA USA, September 3-5, 1986.

[19] D. H. Thompson, J. K. Fink, D. R. Armstrong, B. W. Spencer, and B. R. Sehgal, "Thermal-Hydraulic Aspects of the Large-Scale MCCI Tests in the ACE Program," $2^{\text {nd }}$ CSNI Specialist Meeting on Core Debris-Concrete Interactions, Karlsruhe, Germany, April 1-3, 1992.

[20] J. M. Bonnet and J. M. Seiler, "Coolability of Corium Spread Onto Concrete Under Water, the PERCOLA Model," $2^{n d}$ CSNI Specialist Meeting on Core Debris-Concrete Interactions," Karlsruhe, Germany, April 1-3, 1992.

[21] J. J. Foit, "Modeling of Oxidic Molten Core-Concrete Interaction in WECHSL," Nucl. Eng. Design, 170, 73 (1999).

[22] M. T. Farmer, J. J. Sienicki, and B. W. Spencer, "CORQUENCH: A Model for Gas Sparging-Enhanced, Melt-Water, Film Boiling Heat Transfer," ANS Winter Meeting on the Thermal Hydraulics of Severe Accidents, Washington, D.C. USA, November 11-15, 1990.

[23] M. T. Farmer and B. W. Spencer, "Status of the CORQUENCH Model for Calculation of Ex-Vessel Corium Coolability by an Overlying Water Layer," $O E C D$ Workshop on Ex-Vessel Debris Coolability, Karlsruhe, Germany, November 15-18, 1999.

[24] M. T. Farmer, "Modeling of Ex-Vessel Corium Coolability with the CORQUENCH Code," Proceedings $9^{\text {th }}$ Int. Conf. on Nucl. Eng., Nice, France, April 8-12, 2001.

[25] C. R. B. Lister, "Qualitative Theory on the Deep End of Geothermal Systems," Proceedings 2nd UN Symposium on Development and Use of Geothermal Resources, San Francisco, CA USA, May 20-29, 1975.

[26] M. Epstein, "Dryout Heat Flux During Penetration of Water Into Solidifying Rock," J. Heat Transfer, 128, 847 (2006).
[27] H. Bjornsson, S. Bjornsson, and Th. Sigurgeirsson, "Penetration of Water into Hot Rock Boundaries of Magma at Grimsvotn," Nature, 295, 580 (1982).

[28] B. Tourniaire, J. M. Seiler, J. M. Bonnet, and M. Amblard, "Liquid Ejection Through Orifices by Sparging Gas - The PERCOLA Program," Proceedings $10^{\text {h }}$ Int. Conf. on Nucl. Eng, Arlington, VA USA, April 2-6, 2000.

[29] B. Tourniaire and J. M. Seiler, "Modeling of Viscous and Inviscid Fluid Ejection through Orifices by Sparging Gas," Proceedings ICAPP '04, Pittsburgh, PA USA, June 13-17, 2004.

[30] M. T. Farmer, "Phenomenological Modeling of the Melt Eruption Cooling Mechanism During Molten Corium Concrete Interaction (MCCI)," Paper 6165, Proceedings ICAPP '06, Reno, Nevada USA, June 6-8, 2006.

[31] M. T. Farmer, S. Lomperski, D. J. Kilsdonk, and R. W. Aeschlimann, "OECD MCCI Project Final Report," OECD/ MCCI-2005-TR06 (2006).

[32] T.G. Theofanous, C. Liu, S. Addition, S. Angelini, O. Kymäläinen, and T. Salmassi "In-vessel Coolability and Retention of a Core Melt", Nucl. Eng. Design, 169, 1 (1997).

[33] T.N. Dinh, J.P. Tu, and T.G. Theofanous, "Two-Phase Natural Circulation Flow in AP-1000 In-Vessel Retention - Related ULPU-V Facility Experiments", Proceedings of ICAPP'04, Pittsburgh, PA USA, June 13-17, 2004.

[34] M. Fischer and H. Henning, "EPR ${ }^{\mathrm{TM}}$ Engineered Features for the Mitigation of Severe Accidents," Proceedings ICAPP '09, Tokyo, Japan, May 10-14, 2009.

[35] V.B. Khabensky, V.S. Granovsky, S.V. Bechta, and V.V. Gusarov, "Severe Accident Management Concept of the VVER-1000 and the Justification of Corium Retention in a Crucible-Type Core Catcher," published in Nucl. Eng. Technol., June (2006).

[36] H. Alsmeyer, M. Farmer, F. Ferderer, B. Spencer, and. W. Tromm, "The COMET-Concept for Cooling of Ex-Vessel Corium Melts," Proceedings 6th Int. Conf. on Nucl. Eng., San Diego, CA USA, May 10-14, 1998.

[37] C. Joumeau and H. Alsmeyer, "Validation of the COMET Bottom-Flooding Core-Catcher with Prototypic Corium," Proceedings ICAPP '06, Reno, Nevada USA, June 6-8, 2006.

[38] M. J. Konovalikhin and B. R. Sehgal, "Investigation of Volumetrically Heated Debris Bed Quenching Proceedings $9^{\text {th }}$ Int. Conf. on Nucl. Eng., Nice, France, April 8-12, 2001.

[39] K. Nayak, B. R. Sehgal, and A. V. Stepanyan, "An Experimental Study on Quenching of a Radially-Stratified Heated Porous Bed," Nucl. Eng. Design, 2362189 (2006). 